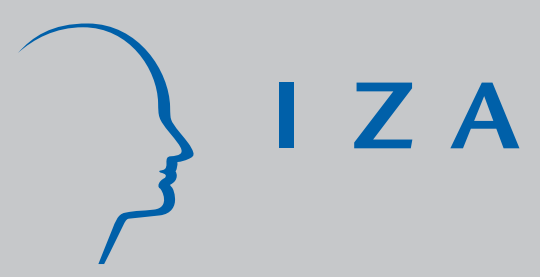

IZA DP No. 1775

Doctor Who?

Who Gets Admission Offers in UK Medical Schools

Wiji Arulampalam

Robin A. Naylor

J eremy Smith

September 2005 


\title{
Doctor Who? \\ Who Gets Admission Offers in \\ UK Medical Schools
}

\author{
Wiji Arulampalam \\ University of Warwick \\ and IZA Bonn
}

\author{
Robin A. Naylor \\ University of Warwick
}

Jeremy Smith

University of Warwick

\section{Discussion Paper No. 1775 \\ September 2005}

\author{
IZA \\ P.O. Box 7240 \\ 53072 Bonn \\ Germany \\ Phone: +49-228-3894-0 \\ Fax: +49-228-3894-180 \\ Email: iza@iza.org
}

\begin{abstract}
Any opinions expressed here are those of the author(s) and not those of the institute. Research disseminated by IZA may include views on policy, but the institute itself takes no institutional policy positions.

The Institute for the Study of Labor (IZA) in Bonn is a local and virtual international research center and a place of communication between science, politics and business. IZA is an independent nonprofit company supported by Deutsche Post World Net. The center is associated with the University of Bonn and offers a stimulating research environment through its research networks, research support, and visitors and doctoral programs. IZA engages in (i) original and internationally competitive research in all fields of labor economics, (ii) development of policy concepts, and (iii) dissemination of research results and concepts to the interested public.
\end{abstract}

IZA Discussion Papers often represent preliminary work and are circulated to encourage discussion. Citation of such a paper should account for its provisional character. A revised version may be available directly from the author. 


\section{ABSTRACT \\ Doctor Who? \\ Who Gets Admission Offers in UK Medical Schools*}

In the context of the UK Government's ambitious programme of medical school expansion, it is important to have an understanding of how the medical school admissions process works, and with what effects. The issue is also relevant for the Schwartz Review (2004) into higher education admissions. Using individual-level data for two entire cohorts of medical student applicants in UK universities and exploiting the panel structure of the applicant-medical school information, we estimate models to analyse the probability that an individual student receives an offer of a place. We find that prior qualifications, school type, gender, age, social class and ethnic background are major influences on whether a student receives an offer from a medical school. We also find that the probability of receiving an offer from a particular medical school is influenced by the identity of other medical schools applied to. Finally, we find evidence that certain groups of applicants are particularly disadvantaged the later they apply within the application process.

JEL Classification: J24, I2, C41

Keywords: medical students, admissions, offer (non-rejection) probabilities, endogenous selection, unobserved heterogeneity

Corresponding author:

Robin A. Naylor

Department of Economics

University of Warwick

Coventry, CV4 7AL

United Kingdom

Email: robin.naylor@warwick.ac.uk

\footnotetext{
* We are grateful to Chris McManus and John Thompson for helpful discussions and to colleagues participating in the Econometrics workshop at Warwick and at the Royal Economic Society Annual Conference, Nottingham, 2005. Financial support from the ESRC under Research Grant no. RES-00022-0303, 'Medical School: Applications, Admissions and progression', is gratefully acknowledged. The data used in the paper was originally made available by the Council of Heads of Medical Schools (CHMS) to Chris McManus. At the time of the start of the analysis for this paper, the data was freely downloadable from www.ucas.ac.uk/new/press/chms. None of these individuals or organisations bears any responsibility for any of the analysis or interpretations presented in this paper.
} 


\section{Introduction}

The UK Government is currently implementing a strategy of expanding the medical school intake in order to train more doctors as recommended by the Medical Workforce Standing Advisory Committee (MWSAC, 1997), which forecast a significant and worsening deficit in the number of trained doctors practising in the UK. The extent of the planned increase in the number of medical school places implies that the total medical school intake will have increased by almost $50 \%$ over a 10-year period from 1997. Expansion on this scale begs challenging questions about the likely impact on the quality of applicants admitted to medical school. For example, will medical schools have to reduce the prior attainment standard required of applicants? This would necessarily be the case if medical schools - over-subscribed with applicants as they are - were able to rank applicants accurately on the basis of their potential ability. If, as is inevitably the case, medical school admissions procedures are imperfect in identifying the best qualified applicants then expansion need not affect quality adversely: so long as the efficiency of admissions policies can be enhanced. In the current paper, we analyse the offer decisions made by medical school admissions selectors, examining how the probability that an applicant's medical school application will generate an offer varies with both applicant and medical school characteristics. If, for example, applicants from particular backgrounds have lower likelihoods of receiving offers, then this might suggest that there is a pool of applicants from which medical students could be drawn without reducing quality.

A further reason for examining medical school decisions on offers relates to the UK debate on the issue of 'widening' access into medical schools. There has been a lively and high-profile debate in the UK concerning the extent of equal accessibility of medical schools to students regardless of their social or school background (see McManus, 1998a and 1998b). This has led to explicit recommendations to broaden access to undergraduate medical education (Angel and Johnson, 2000). Behind this call are two major arguments. One is that by reaching out to non-traditional communities, applicants with potentially high ability will be encouraged to apply to medical schools. Smith and Naylor (2001) have shown that candidates from less privileged backgrounds are more likely to perform well at university than are otherwise similar students. A second argument is that qualified doctors will be better 
able to serve their patients the more they are able to reflect the characteristics of their communities in terms of gender, ethnicity and social class composition: see the report by the Board of Medical Education, 2004. We are particularly interested in how the probability of receiving an offer varies by the gender, ethnicity, age and social class of the applicant.

More generally, there is considerable current discussion about radical changes to national admissions policy for higher education. The Schwartz Report (2004), for example, has recently made a number of recommendations, including a shift towards a post-qualifications admissions procedure to replace the current system by which the typical applicant applies to university prior to completing their secondary education. Currently, the Department for Education and Skills is consulting over proposals on post-qualification higher education entry: see DfES, 2005. Our paper attempts to inform this debate.

A final reason for examining offers is the extensive literature which suggests that the quality of the university/college into which one is admitted affects subsequent earnings: see, for example, Loury and Garman (1995) and Brewer, Eide and Ehrenberg (1999) for the US and Chevalier and Conlon (2003) for the UK.

Our work complements and extends earlier work by McManus (1998a, 1998b), whose analysis focused primarily on the issue of whether particular groups of applicants were disadvantaged in the medical school selection process. We discuss McManus' findings in more detail and the relationship to our work in Section 2 of the paper.

The rest of this paper is organised as follows. Section 2 presents a discussion of the institutional and policy contexts, which provide the backdrop to our analysis of data on UK medical student offers. Section 3 describes the data set. The statistical model is presented in Section 4 along with the discussion of the results. Finally, Section 5 closes the paper with conclusions and further remarks.

\section{Institutional context and public policy}

This paper uses data from the cohorts of applicants in 1995 and 1996 (for entry in 1996 and 1997 respectively), just before the expansion of student numbers, to look at the question of which students were made offers in response to their medical school application. In terms of the issue of widening participation and addressing the related issue of equality of treatment across students, it is important to examine data 
on medical school offers to test for evidence of factors which affect the probability that an applicant receives an offer (rather than a rejection). In one sense, a "fair” and “efficient" admissions policy might be expected to be one in which the student's probability of receiving an offer was independent of characteristics other than their likely A-level (a typical pre-university qualification) outcome. However, A-level scores might not be perfectly correlated with potential relevant ability for medical student performance and other characteristics might be relevant. For example, there is evidence that applicants for UK university who have been to a state-sector school are, on average, of higher potential ability than otherwise observationally equivalent applicants from Independent schools (Smith and Naylor (2001)). In this case, equal access admissions policies to students of equivalent potential ability might be associated with a role for school background affecting the probability of receiving an offer.

The "fairness" issue is also related to the possible impact on student "quality" associated with expansion. Suppose that, pre-expansion, the probability of a medical school applicant receiving an offer of a place is significantly related to characteristics uncorrelated with the student's potential ability to perform well as a medical student. Then this would indicate that there is scope for producing more efficient admissions policies in such a way as to at least mitigate any adverse effects on quality associated with increasing the number of students accepted into medical schools. This is a key focus of the current paper.

As noted above, our work is closely related to that of McManus (1998a, 1998b), whose work was commissioned by the Council of Heads of Medical Schools (CHMS) primarily to examine whether there was any evidence of any particular group of applicants being disadvantaged in the admissions process. Carrying out the analysis at each medical school level, McManus (1998b) estimates a logit model for the probability that an applicant will receive an offer from a medical school. Among other results, McManus concludes that although A-level grades are strong predictors of the probability of receiving an offer, there is evidence of disadvantage for males, applicants from ethnic minority backgrounds, those from $6^{\text {th }}$ Form and Further Education (FE) Colleges, non-local applicants to university, those from lower social class groups and those applying late. In part, our analysis attempts to build on the work of McManus in particular directions. We use the same dataset but, as we explain in more detail below, adopt different statistical models in order to focus in more detail 
on specific current policy-relevant issues such as the effect of the timing of the application. One of the key differences between our analysis and that of McManus is that, instead of regarding all applicants' medical school applications as independent essentially pooling the data across applicants - we treat the data as a panel in which the dependent variable is the probability that student $i$ receives an offer from school $j$. Hence, we exploit our knowledge about which applications each applicant makes in order to allow for applicant-specific common factors across applications made by the same applicant. Thus, we are able to control for unobserved heterogeneity across applicants. This is likely to be important because offers are likely to be influenced by characteristics of applicants observed by medical schools - for example, in references, personal statements and interviews - but not recorded in the dataset and hence unobservable by the researcher. Our panel set-up, provides a way of controlling for unobserved characteristic that are common across the individual applicant's different medical school applications but varying across applicants. In addition, we also allow for the possibility of endogeneity of the choice of the number of medical school to which the applicant applies.

\section{The Data}

All admissions to UK universities for full-time undergraduate courses are through a central organisation which processes applications. This organisation is the Universities and Colleges Admissions Service (UCAS). For applications made for entry in 1996 and 1997 an applicant was permitted to apply through UCAS for a maximum of six distinct university courses and five in the case of medical applications (more recently applicants have been restricted to a maximum of 4 applications to medical school). There are no additional restrictions on what courseuniversity combination one can apply for, with the exception that each applicant is permitted to apply to only one of Oxford or Cambridge. In each annual round during the period we analyse, the closing date for applications is mid-December (or midOctober in the case of applicants to Oxford and Cambridge) of the calendar year prior to University entry. It follows that applicants intending to proceed from school to higher education within the same year - that is, not postponing their application beyond a 'gap year' interval - will submit their application form prior to the completion of their school studies and hence without knowledge of their final school grades (that is, A-level, in the majority of cases of applicants from England, Wales 
and Northern Ireland, and Highers for Scottish students). In what follows our discussion is based on the standard case of an applicant applying during their final school year.

For the standard case, university responses to applicants are also made prior to applicants taking their final school examinations. In such cases, the university reply can either be a rejection of the application or an offer of a place. Such an offer would be made conditional on the applicant achieving certain minimum grades. Some institutions also interview candidates, a practice which is particularly prevalent in medical schools. Finally, applicants must respond to offers before they have taken their final school examinations. Each applicant can accept a maximum of two offers: one being a 'firm' acceptance and the other being an 'insurance' acceptance. Applicants who obtain grades which satisfy the conditions of their firmly-accepted conditional offer are committed to going to that university and the university is committed to taking them. If the applicant's grades fall below the offer required, they might nonetheless be accepted by their firmly-accepted university if the course has unfilled places. However, if the under-achieving applicant is not taken by the university whose conditional offer they firmly accepted, that university releases the applicant from their 'contract'. At this point, provided that the applicant's grades meet the conditions of the 'insurance-accept' course, both these parties are committed to this offer/accept contract. Again, students whose grades fall below both the insuranceaccepted conditional offer might still be offered a place if there are unfilled vacancies. Otherwise the student is again released from the contract, in which event they are entitled to enter into a 'clearing' process (administered by UCAS), in which unplaced applicants match themselves with unfilled university places. Medical schools rarely enter into this clearing process. Generally, failed medical school applicants will either choose to do some other course (through clearing), or apply to medical schools the following year, perhaps resitting some of their examinations in an effort to improve their grades.

Some students take a gap year prior to entering higher education. These students can choose between applying during their final school year - as described above - for a deferred university place or, alternatively, applying in the subsequent admissions round once they have received their final school grades. In this latter case, both the applicant and the institution to which the application has been made have full information about grades achieved. The university response to an application is then 
either to reject or to make an unconditional offer. The student made one or more unconditional offers may firmly accept only one unconditional offer. ${ }^{1}$

University department admissions tutors determine admission policies for their courses in order to achieve various objectives and to satisfy particular constraints. Most crucially, they aim to recruit the ablest applicants while equating the number of entrants to a target entry population. Many pieces of information contained in the application form might be taken into account - including a personal statement, a school reference and predicted grades - in making an offer and setting a conditional grade requirement. The distribution of the grades offered to applicants for a particular university course will be set so that the predicted number accepting and then satisfying the conditions of that offer will be equal to the number of places available. While conditional offers to students may vary in terms of the conditions of the offer, all courses (including medical school courses) have a typical offer reported in the UCAS handbook, which is the basis for the offer made to each applicant. Offers may vary according to different characteristics of the applicant. Typically, admissions tutors have discretion over the precise offer made in each case. Ceteris paribus, the higher the typical offer set by the medical school, the smaller will be the number of successful applicants. ${ }^{2}$ Thus, the typical offer acts as a rationing device. If demand for a particular university course grows over time, then there will be a tendency for the required grades to grow too. This is also likely to lead to a better qualified and higher ability entry cohort on to the degree course, other things equal. Against this, there is the risk that high offers will preclude entry from potential students with high ability but relatively poor pre-university schooling opportunities. This issue is very relevant for recent debates on access into UK higher education.

In this paper, we use data on all applications that were made by students to any medical school in the UK for entry in either 1996 or 1997. For 1996 entry, there were 44,353 applications made by 9,520 distinct applicants. The corresponding figures for 1997 were very similar to those in the previous year, with 44,629 applications made

\footnotetext{
${ }^{1}$ As we are unable to distinguish between applicants who are making applications on the basis of known results and those who apply without any knowledge of their A-level or Higher results and hence cannot distinguish between a conditional and an unconditional offer. Hence we will be concerned with modelling the probability of not receiving a rejection to an application to a particular medical school.

${ }^{2}$ Although, especially in a dynamic setting, there might be a tendency for the number of applicants (and firmly-accepted offers) to increase as the offer increases. This might occur, for example, if the offer acts as a signal of institutional quality.
} 
by 9,513 distinct applicants. The number of applications received (relative to the number of places available) across the different medical schools is shown in Figure 1 and varies from around 22 at Imperial to around 2.7 at Queens University, Belfast. While the medical schools recommend that applicants apply to no more than five medical schools, there are quite marked differences in the number of applications that applicants made, with approximately 3\% applying to only one medical school, $2 \%$ applying to each of two and three medical schools, 7\% applying to four medical schools, $80 \%$ applying to five medical schools and 5\% applying to six medical schools. Approximately 5\% of applicants make an application to at least one nonmedical school course.

From all of these 44,353 $(44,629)$ applications received for entry in 1996 (1997), medical schools made 10,664 $(10,399)$ offers, corresponding to an offer-toapplication ratio of approximately 24\% (23\%). Figure 2 clearly shows that this ratio differs markedly across medical schools, from a high of around 70\% for Queens University, Belfast to a low of around 10\% for the University of Nottingham.

If we look at the number of offers made across applicants we find that in both 1996 and 1997, approximately 41\% of applicants receive no offer of a place in a medical school, $24 \%$ receive one offer, $17 \%$ two offers, $11 \%$ three offers, $5 \%$ four offers and $2 \%$ five offers. No students are made six offers. Given that $85 \%$ (92\%) of students apply to at least five (four) medical schools, it is surprising that only $2 \%$ (7\%) of students receive at least five (four) offers. The figures suggest considerable discernment on the part of Medical Schools in the offer decision, which is of course the focus of the analysis conducted in the current paper.

Table 1 presents summary statistics on some of our key variables. In Table 1a summary statistics are provided separately for the $1,542(1,313)$ applicants who applied to between 1 and 4 medical schools and on those 7,977 (8,200) who applied to either 5 or 6 schools in 1996 (1997). Table 1b distinguishes between those 4,028 $(3,986)$ applicants who received no offer and those $5,492(5,527)$ who received at least one offer in 1996 (1997).

From Table 1a, we see that in both years males make up around $48 \%$ of all applicants. However, it emerges from Table 1b that males make up 54\% of those applicants who received zero offers, and, in contrast, only $45 \%$ of those who received at least one offer. On ethnicity, Table 1a shows that white students make up 63\% of all applicants, on average, while Table 1b shows that they comprise only around 50\% 
of those applicants who received zero offers and $72 \%$ of those who received at least one offer. Thus, the raw summary statistics support findings both in the UK (see Leslie, Abbott and Blackaby (2002)) and in the US (Light and Strayer (2002)) that individuals from ethnic minority backgrounds struggle to be accepted into universities. In terms of social class background, we find that applicants from a Social Class I (Professional) background make up 34\% of all applicants. However, these applicants comprise only $29 \%$ of those with zero offers and $48 \%$ of those with at least one offer. Seyan, Greenhalgh and Dorling (2004) calculate standardised admission ratios using data from UCAS and from the Labour Force Survey. They report ratios for various sub-groups and find enormous differences by ethnicity and social class (see also Hilton and Lewis, 2004).

In this dataset we do not have access to predicted A-level or Higher grades and use actual A-level and Higher grades instead, as these are very highly correlated with the predictions. Lumb and Vail (1997) report that A-level predictions for medical school applicants are highly correlated with subsequent actual A-level results. Across all subjects, Hayward, Sturdy and James (1997) find the accuracy of predictions to vary by gender, socioeconomic status, previous educational institution and examination board but, most of all, by ethnicity. Large variation in predictions by ethnicity is also found by and Shiner and Modood (2002). However, given the high concentration of medical school applicants in the upper tail of the A-level distribution, it is perhaps not surprising that predictions for these students tends to be more accurate. Within the data, we also have performance in A-level (and Higher) broken down by science and non-science subjects. ${ }^{3}$ Table 1 shows a marked difference in Alevel performance (in the science subjects) according to whether an offer is received. Compared to students with zero offers, those receiving offers have a higher average A-level score in science subjects, a higher score in other subjects and are less likely to have re-sat a science A-level. Among applicants with Scottish Highers, having a CSYS certificate is associated with a higher probability of receiving an offer, according to the raw data.

One of the key areas of potential expansion in the Government's policy of widening participation is related to age. From Table 1 we find that around $40 \%$ of applications (and applicants) were aged over 18 years old, yet this group of applicants

\footnotetext{
${ }^{3}$ A-levels are classified as $A=10$ points, $B=8$ points, $C=6$ points, $D=4$ points and $E=2$ points.
} 
make up less than $30 \%$ of those applicants receiving an offer. If we look at the region of residence we note that nearly $40 \%$ of all applications came from the London and the South East of England. We also report the proportion of the applications which were to a local medical school. From the raw data, the date of submission of an application appears to be important for the likely success of the application. For example, we note from Table 1 that December applicants make up around 30\% of all UCAS forms received, but comprise only $21 \%$ of those applicants receiving at least one offer.

For the period under analysis, as we have noted, there were some differences in the date of application deadline by medical school and, related to this, the dataset contains information on the date at which the applicant submitted their application form - which for each applicant is common across each of their applications because of the single, centralised application process. From this, we are able to investigate date-of-application effects in the probability of success of an application. More recent cohorts face a single early application deadline, which precludes the possibility of a reliable date-of-application analysis. This is a further reason for exploiting the datasets used in our current analysis. From Table 1a, we note that of those making at least 5 applications to medical school for entry in 1996 (1997), about 20\% (30\%) applied in October, 53\% (47\%) in November, 28\% (23\%) in December and 2\% (2\%) were late. From Table 1b, we can see that the distribution of those receiving at least one offer is relatively skewed towards earlier applicants compared to the distribution by applicant date among those not receiving an offer.

\section{Statistical Model and Results}

Receiving an offer of a place from a medical school is conditional on the individual applying to that medical school. A student can apply to up to 6 medical schools when s/he makes an application. We model the probability that student $i$ will receive an offer from medical school $j$, conditional on applying to $n_{i}$ medical schools, as a panel probit model with random effects for individuals and fixed effects for medical schools. That is,

$$
\operatorname{Pr}\left[Y_{i j}=1\right]=\Phi\left[\alpha_{0}+\sum_{g=1}^{26} \alpha_{g} D_{i j g}+\beta^{\prime} x_{i j}+\eta_{i}+u_{i j}\right] \quad i=1, \ldots N, j=1, \ldots n_{i}
$$


where $\Phi$ is the cdf of a standard normal distribution and $Y_{i j}=1$ if student $i=1, \ldots N$ receives an offer from medical school $j$, with $j=1, \ldots, n_{i}$ and $n_{i} \leq 6 . D_{i g}$ is a binary indicator which takes the value of one if an application is made to medical school $g$. In addition to various individual specific characteristics in $x$, we also include the number of applications the student had made. We note that an important difference between our analysis and that of McManus (1998b) is our treatment of the data as a panel in which the dependent variable is the probability that student $i$ receives an offer from school $j$. We exploit our knowledge about which applications each applicant makes and hence we are able to allow for applicant-specific common factors across applications made by the same applicant. In contrast, McManus (1998b) conducts a pooled analysis in which all applications are assumed to be independent. An important and novel feature of our analysis in this context, then, is that we are able to control for unobserved heterogeneity across applicants. This is likely to be important because offers are likely to be influenced by characteristics of applicants (such as the personal statement, school reference, performance at the interview, etc.) observed by medical schools, but unobservable by the researcher.

A test of $\mathrm{H}_{0}: \sigma_{\eta}^{2}=0$ is a test that there are no unobservable individual characteristics in the model. This can be tested using a likelihood ratio (LR) (or a standard normal test statistic) but the test statistic will not have a standard $\chi^{2}$ (or a standard normal) distribution since the parameter under the null is on the boundary of the parameter space. The standard LR (normal) test statistic has a probability mass of 0.5 at zero and $0.5 \chi^{2}(1)(0.5 \mathrm{~N}(0,1))$ for positive values. Thus a one-sided $5 \%$ significance level test requires the use of the $10 \%$ critical value (Lawless (1987), Andrews (2001)).

In the vector $x_{i j}$ we wish to include controls on those other medical schools to which the applicant applied, that is,

$$
D_{i j g}^{k}=\left\{\begin{array}{lr}
1 & \text { if applied to university } k \neq g \\
0 & \text { otherwise }
\end{array},\right.
$$

However, parameter constraints prevent us from looking at the complete matrix of interactions as this would entail estimating 702 parameters. As a compromise, we look at interactions between different medical school types, classified as: Oxbridge (Oxford and Cambridge), Scottish (Aberdeen, Dundee, Edinburgh, Glasgow and St. 
Andrews), London (Charing Cross, Imperial College, Kings’ College, Queen Mary and Westfield (QMW), Royal Holloway, St. George, Guys and St Thomas and University College London (UCL)), Other English (Birmingham, Bristol, Leeds, Leicester, Liverpool, Manchester, Newcastle, Nottingham, Sheffield and Southampton ) and Other (Wales Medical School and Queens Belfast). In our model specification we therefore include

$$
D_{i j h}^{l}=\left\{\begin{array}{rr}
1 & \text { if applied to university type } l \\
0 & \text { otherwise }
\end{array}, h=1, \ldots 5 \text {, and } l=1, \ldots 5 .\right.
$$

example, Edinburgh also has an application in some other Scottish university, or in Oxbridge, London, Other English or Other university. In total this involves including 24 dummy variables for all possible interaction terms, excluding the dummy variable in recognition of the fact that one cannot apply to both Oxbridge universities.

As discussed above, most of the students apply to at least 5 medical schools with a small proportion of students applying to less than 5. In order to account for the possible endogeneity of this choice, we specify a probit model

$$
\operatorname{Pr}\left[a_{i}=1\right]=\Phi\left[\gamma_{0}+\gamma^{\prime} z_{i}+\theta \eta_{i}+u_{i 0}\right] \quad i=1, \ldots N
$$

where, $a_{i}=1$ if student $i$ applies to less than 5 medical schools and $u_{i 0} \sim N(0,1)$. The vector of covariates $z$ includes personal characteristics as well as the pre-university qualifications. In addition, in order to achieve identification, we have also included the square of the A-level and Highers scores. To allow for the possibility of endogeneity of the number of medical schools applied to, we have allowed the individual specific unobservable error term $\eta_{i}$ to enter (4) with a coefficient $\theta$. Clearly, if $\theta=0$ then unobservables in equation (1) are uncorrelated with unobservables in the selection equation given by (4). Hence, a test of $\theta=0$ is a test of exogeneity of the number of applications variable that enters equation (1).

Given the above distributional assumptions, the model can be easily estimated by noting that, conditional on $\eta_{i}$, the distribution of the sequence of binary indicators $Y_{i 1}, Y_{i 2}, \ldots, Y_{i n}, a_{i}$ are independent normal. Hence, the joint probability of the observed sequence of binary indicators for individual $i$, taking into account of the possibility of endogenous choice of the number of medical school applications, is therefore 


$$
\mathrm{P}\left(Y_{i 1}, \ldots, Y_{i n_{i}}, a_{i} \mid \eta_{i}, . .\right)=\prod_{j=1}^{n_{i}} \Phi\left[\left(\alpha_{0}+\sum_{g=1}^{26} \alpha_{g} D_{i j g}+\beta^{\prime} x_{i j}+\eta_{i}\right)\left(2 y_{i j}-1\right)\right] \Phi\left[\gamma_{0}+\gamma^{\prime} z_{i}+\theta \eta_{i}\right]
$$

Under the assumption that the individual specific random error $\eta_{i} \sim N\left(0, \sigma_{\eta}^{2}\right)$, the likelihood contribution of individual $i$ is

$$
L_{i}=\int\left\{\prod_{j=1}^{n_{i}} \Phi\left[\left(\alpha_{0}+\sum_{g=1}^{26} \alpha_{g} D_{i j g}+\beta^{\prime} x_{i j}+\sigma_{\eta} \tilde{\eta}_{i}\right)\left(2 y_{i j}-1\right)\right] \Phi\left[\gamma_{0}+\gamma^{\prime} z_{i}+\theta \sigma_{\eta} \tilde{\eta}_{i}\right]\right\} \varphi\left(\tilde{\eta}_{i}\right) d\left(\tilde{\eta}_{i}\right)
$$

where $\tilde{\eta}_{i}=\eta_{i} / \sigma_{\eta}$ and $\phi$ is the normal density function.

We estimate two versions of our model for the probability of receiving an offer. The first treats the number of applications made as exogenous and is based solely on equation (1). This involves setting $\theta=0$ in (4). Under this restriction, it is easily seen from (6) that, the likelihood function factors into two components with one component referring to a random effects probit model and the other a simple probit. The results from this random effects probit model are presented in columns [1] and [3] of Table 2 for each of the two years, 1996 and 1997. The second models equations (1) and (4) jointly and hence allows for endogeneity. The estimated coefficients from this model are reported in columns [2] and [4] of Table 2. Results for the model on the probability of making fewer than five applications are not presented here, but are available from the authors upon request. ${ }^{4}$

We turn now to discuss the main results. Table 2 presents estimated coefficients for both years for both the model with and the model without allowance for endogeneity of the choice of the number of applications. In Table 3, for illustrative purposes, we present some marginal effects calculations for some of the variables of interest. We note that the estimated effects are similar in the two models, though the pattern of significance shows variations depending on whether we treat the number of medical schools chosen as endogenous or not. As we saw earlier, a test for this endogeneity is given by a test of zero coefficient restriction on $\theta$ and this is rejected at conventional degrees of freedom (see Table 2). We also note from Table 2 that a test of $\mathrm{H}_{0}: \sigma_{\eta}{ }^{2}=0$ is rejected at conventional level of significance suggesting the

\footnotetext{
${ }^{4}$ It has been suggested to us that the small proportion of students who apply to 6 medical schools might be unusual cases and hence their inclusion in the analysis might be biasing the results. We have re-run models excluding these cases and find that our results are robust to the exclusion of these cases.
} 
importance of allowing for unobservables in the model. Various sub-sections discuss results for the chief categories of explanatory variables employed in the analysis. Section 4.5 reports the effects of the date of application and the results of a more detailed study in which we estimate the random effects probit model, with endogeneity, separately for October, November and December applications.

\subsection{Medical School effects}

We note that there are strong university effects in the probability of an application receiving an offer. We note that applications to Aberdeen, Charing Cross, Dundee, Glasgow, Leicester, Liverpool, Manchester, QMW, Queens, Royal Holloway, St. Andrews and St. George are all markedly (and significantly) are more likely to receive an offer relative to an application to the default reference case (Kings College) in both 1996 and 1997. By contrast only applications to Bristol, Imperial and Nottingham are significantly less likely to receive an offer in both years. In trying to investigate these medical school effects further, we regressed the medical school coefficient estimates against a series of medical school characteristics and found a highly significant and negative effect associated with the medical school staff-student ratio, but a positive and significant effect for those medical schools which have a higher salary bill per member of staff. The estimated effects control for the applicants' prior qualifications but are conditional on an application being made. We leave further analysis of individual school effects and of their interactions with other explanatory variables for further work.

\subsection{Medical School interaction effects}

In addition to the individual university effects, we note there is evidence of significant interaction effects between the types of medical schools to which an applicant has applied. We note that for an application to an Oxbridge medical school, there does not appear to be any consistent and strong effects associated with having an application to any other type of medical school, with the possible exception of a negative effect of having an application at a London University in 1996 (the p-value for the joint significance of the four interaction terms in 1996 (1997) is 0.31 (0.24)). By contrast, for applications to a Scottish medical school, there is a very strong and significant positive effect of also having an application at Oxbridge or at another Scottish University. There are also significant negative effects of having an application at a London University medical school or at a medical school in the Other University category. 
For an application to a London medical school, we note there is a significant negative effect from having an application to another London university. But there are significant positive effects from having an application at Oxbridge and Other English universities. For an application to an Other English medical school there is a significant negative effect from having an application at a London university. Again there is a significant positive effect from also having an Oxbridge application or Other English. Finally, for those who have an application at an Other medical school there again is a positive Oxbridge effect. There is negative effect of a London application and from having an application at the Other medical school group.

These effects are interesting as they are significant over and above the university one has applied for and control also for both regional variables and for the observable personal characteristics of the applicant, including their actual performance in their pre-university school examinations. There are various possible explanations for these interaction effects, though we are not able to distinguish between them in the current paper. It might be that admissions tutors are looking for students who are committed to their particular type of university, defined for example by region or reputation. Alternatively, it might be that information about the extent of the student's ability or ambition which is deemed to be indicated by the type of university to which the applicant applies. Further, it might be that the admissions tutor is seeking to reject applicants perceived to have a low probability of accepting an offer, and this could be linked to the set of other universities to which an application has been made. Again, we leave a detailed investigation of these institutional effects to further work.

\subsection{Personal characteristics}

In the summary statistics for the raw data we observed that males were markedly less likely to receive an offer from a medical school, compared to females. This observation holds also in the multivariate analysis. In Table 2 we find that, ceteris paribus, the estimated coefficient for males is negative and significant in both models in both years. We have derived three marginal effects (MEs) for selected variables. These are shown in Table 3. The first ME is derived from the model in which the number of applications made by each individual is treated as exogenous. The second and third columns present MEs derived from the model with endogeneity (the details of the calculations are provided in the Appendix). The second column shows conditional MEs while the third column presents unconditional MEs, which take 
account of the estimated effects of the explanatory variable on the probability of applying to fewer than five medical schools. From Table 3, we see that males are around 5 percentage points less likely to be made an offer than are females, with the unconditional marginal effect of being male a little lower than the conditional. Given the cost of a medical degree and the Government focus on progression as a measure of university success, a policy which increases the likelihood of females being offered a place, could be justified as Arulampalam, Naylor and Smith (2004a, 2004b), find that females are markedly less likely to dropout of a medical degree. It is not clear, however, whether this is the true explanation underlying the finding.

We also find that all non-white ethnic applicants are significantly less likely to be made an offer compared to otherwise (in our data) observationally equivalent white students. We observe some differences across the different ethnic groups, with a particular disadvantage for Pakistani students who, as we can see from Table 3, are around 10 percentage points less likely to be made an offer, relative to white students.

In relation to the age groupings, we note applications received from applicants aged over 19 years are much less likely to yield an offer, compared to 18 year olds. For example, the probability of an offer for applicants aged 20 is about 6 or 7 percentage points less than that for an 18 year old applicant, other things constant. Arulampalam et al. (2004a) find evidence of more mature medical students having a slightly higher dropout rate. Again, it could be that admissions selectors are taking this into account when making offers.

Compared to an application received from an applicant from Social Class II (Intermediate), an application received from a person with a Social Class I (Professional) background is around 1 to 2 percentage points more likely to receive an offer of a place on a medical course for entry in 1996. The other social class variables are largely insignificant, but suggest that applicants from a lower social class are less likely to receive an offer. In this case Arulampalam et al. (2004a and 2004b) found only weak social class effects on the probability of student progression, although did find that students who had a parent who was a medical practitioner was markedly less likely to dropout of their studies. In this dataset we cannot identify applicants whose parent is a medical practitioner, other than noting they would be in the Social Class I (Professional) category.

On residence effects, there is little with the exception that individuals applying from Scotland or Northern Ireland are substantially less likely to be made an offer, 
compared to somebody from Greater London. Given that the model includes controls for Higher qualifications, this result is surprising. There is some evidence in 1996, at least, of an advantage from having come from Wales and the South West of England. As part of the regional effect we construct a variable to reflect the proportion of an individual's applications that are local and then divide this into a categorical variable. As can be seen from the results the only effect we observe is that applications from applicants who have applied only to local medical schools are some 4.5 percentage points more likely to receive an offer, compared to the application where none of the applications are local.

While there is little evidence in Arulampalam et al. (2004a or 2004b) of any schooling effect, we find that having been to an Independent school or Grammar schools raises the probability of an offer by between 1-3 percentage points compared to somebody from a comprehensive (Local Education Authority, LEA) school. Having come from a FE college reduces the probability by around 4 percentage points. Interestingly, McManus (1998b) finds no Independent school effect relative to comprehensive school applicants.

\subsection{Prior Qualifications}

Table 3 indicates that every extra science A-level point (equivalent to half of an Alevel grade) increases the probability of an offer by around 3 to 4 percentage points, whereas an extra non-science A-level grade increases the probability of an offer by less than one-quarter of that amount, at about 1 percentage point or less. Whereas medical schools have undertaken - through widening access programmes (see Secretary of State for Education (2004) - a policy to change the entry requirements to be less reliant on the 3 standard science subjects (Biology, Chemistry and Physics), we find that applicants who studied 0 or 1 (2) A-level science subjects are 11 (6) percentage point less likely to be made an offer, compared to somebody with 3 Alevels in science. Individuals with 4 A-levels in science have an increase in probability of an offer by around 3 percentage points. There is no clear and consistent evidence of an advantage of having studied more than 4 science A-levels. If any of the A-levels is a resit A-level then this reduces the probability of an offer by around 10 percentage points.

For applicants from Scotland, having a CSYS (Certificate of Sixth Year Studies and is a qualification above the standard Higher) significantly increases the probability of an offer compared to the average student: the positive marginal effects 
is in the region of 10-14 percentage points, In the Highers exams, every extra grade in a science subject increase the probability of an offer by around 5 percentage points. This figure compares to a much smaller 1.5 percentage point reduction in the probability of an offer for an extra grade in a non-science subject. We find that having fewer than 4 science Highers reduces the probability of an application yielding an offer by at least 10 percentage points. This pattern for Highers is, then, similar to that for A-level subjects.

From Table 2 we see that applications with fewer than four other medical school applications are significantly less likely to generate an offer, for both models for both years. The derived marginal effects shown in Table 3 indicate that the probability of an offer is lower by around 5 percentage points for these applicants. This result could indicate a kind of scarring by which candidates with a smaller number of medical school applications are seen by selectors as less committed to a medical degree. We note that $\theta$ is positive and highly significant for both years in the model which accounts for endogeneity of the number of applications made. This suggests that those unobserved characteristics which are associated with a higher probability of applying to fewer than 5 medical schools are associated with a higher probability of receiving an offer. We note that this is operating in the opposite direction to the observable characteristic regarding the number of medical applications. From Table 2, we also see that applications which include at least one non-medical application are significantly less likely to receive an offer. Previous applications do not seem to either benefit or hinder the prospect of an offer. It is possible that the number of applications made by the applicant acts as a signal of the applicant's commitment to a medical degree.

Summarising our results to this point, then, we find that in terms of the probability of receiving an offer, there is a disadvantage for: (i) males, (ii) older applicants, (iii) applicants from lower Social Class groups, (iv) applicants from nonwhite ethnic backgrounds - and for Pakistani applicants in particular, (v) applicants to non-local universities, (vi) applicants from schools other than Independent or Grammar schools - especially for those from Further Education colleges, and (vii) applicants with fewer than 5 medical application. Additionally, and unsurprisingly, a better performance in prior qualifications is a strong prediction of success in terms of the probability of receiving an offer of a place at medical school. We note that 
applicants with more science subjects at either A-level or Higher tend to be more likely to receive an offer and there is a particular premium associated with a good average score in prior science subjects taken.

\subsection{Date of Application}

Table 2 shows that compared to applicants made in November, applicants made in October (December) are significantly more (less) likely to receive an offer, ceteris paribus. There appears to be a monotonic effect in the timing of the application, with later candidates less likely to receive an offer than earlier candidates. Table 3 shows that the corresponding derived marginal effects are substantial. In 1996, for example, the conditional marginal effect for an application in October was plus 5 percentage points over a November application while a December application carried a penalty of about 8 percentage points relative to a November submission. It is interesting to note that Lumb and Vail (1997) report that students who applied earlier were more likely to make the grades specified in the conditional offer.

From our results, there is clearly a huge benefit associated with applying earlier in the selection process, even though the closing date for (non-Oxbridge) candidates is later than the date of application defining even the December applicants in our analysis. What might explain the importance of the date of application? Various hypotheses might be put forward. First, it could be that earlier applications have characteristics which are more desirable to the selectors. For example, the October applicants will include all Oxbridge candidates and these students will probably have more A grades in their predicted grades and these grades are generally easier to predict (see Lumb and Vail (1997)). However, we control both for prior qualifications and for other medical schools applied for. This might leave a role for characteristics observed by the selector but not available in our dataset: such as information revealed in either an interview or in a personal statement on an application form. A second hypothesis could be that an earlier application itself conveys a signal that the applicant is more committed to a medical school programme. This could lead admissions selectors to favour such candidates. A third hypothesis is that - at least in the two cohorts we observe - admissions selectors have to adjust their offer probabilities downwards over time as they revise predictions about the pressure on available places. This should not be an issue in steady-state with full information as selectors would be able to post a fixed offer condition independent of the point in the admissions cycle. But with exogenous shocks and disequilibrium, updating might 
mean that selectors change their offer rates during the selection round in order to equate expected demand to the fixed supply of places. If demand is greater than predicted at the start of the process, then updating will lead to a reduced offer probability for later applicants, ceteris paribus.

In order to investigate the effect of the date of application in more detail we have estimated our random effects probit model, accounting for endogeneity, separately for each of the 3 months (October, November and December) for which applications are registered. Implicitly, of course, we are assuming that the month of application is an exogenous variable. This does not seem to be an unreasonable assumption as it is typically the school rather than the individual applicant which determines the date of application for all of its pupils. The results of this analysis are reported in Table 4, for selected variables: the estimated equations are the same as those for the model reported in Table 2 for the model with endogeneity. For reasons of space, we report only the results for entry in 1996, though the results for 1997 entry are very similar. From Table 4, one picture which emerges is the following. Characteristics which are associated with a lower probability of receiving an offer tend to have a more disadvantageous effect on the non-rejection probability for candidates applying later in the admissions round. This is true for the following characteristics: male, Pakistani, and low proportion of local medical schools applied for. Similarly, the disadvantage associated with having previously studied in a Further Education college, relative to a comprehensive (LEA) school, is found to be significant only for the November and December applicants, while the advantageous effect for those from Grammar or Independent schools is significant only among nonOctober candidates. There is also evidence that the premium for a good performance in prior qualifications is stronger for later candidates. For example, the advantage for Scottish Higher students associated with having the CSYS certificate is stronger for later applicants, while the penalties for re-sitting are also greater for the later candidates.

Finally, we note that there are particularly interesting differences across date of application associated with the number of medical schools applied for. There is a significant advantage associated with applying to less than 5 medical schools for those applying in October. This might be because admissions selectors perceive such candidates to have a particularly strong preference for their specified medical schools and to have a consequently more predictable 'response-to-offer' probability. In 
contrast, applying to fewer than 5 medical schools for later applicants carries a significant and substantial disadvantage. It is as if such candidates are scarred by appearing to be relatively uncommitted to medical school. If this interpretation is correct, it implies that the signals carry meanings which are time-dependent.

Table 4 also reports the estimate of $\theta$ for each application month. For December applicants, the estimated value of $\theta$ is positive and significant, as was the case when all months were aggregated in the model reported in Table 2. The interpretation is that unobserved characteristics associated with a higher probability of applying to fewer than 5 medical schools are associated with a higher probability of receiving an offer. The unobservables are working in the opposite direction to the observable characteristic of the number of medical applications. For the November applicants, the estimated value of $\theta$ is not significant. For October applicants, however, the estimate of $\theta$ has switched sign and is now negative. However, it is again working against the observable effect of having made fewer than 5 medical applications as this now has a positive sign, as noted above.

We conclude that there is evidence from our separate models by application date to suggest - at least for the two years under study - that not only is timing of application to medical school important in itself, but also that the influence of particular characteristics on the probability of receiving an offer varies with the timing of the offer. We suggest that our results are consistent with an admissions process which not only disadvantages certain groups of applicants, but which disadvantages them particularly strongly later in the process when pressure on places is likely to be particularly intense. One policy implication of this is that a post-qualification admissions process - as proposed in the Schwartz Report (2004) - might alleviate the acutest instances of inequity and inefficiency.

\section{Conclusions}

The UK Government has launched an ambitious programme of medical school expansion, part of which involves encouragement to medical schools to widen their recruitment and selection strategies to students from less traditional backgrounds. In this context, it is important to have an understanding of how the medical school admissions process works, and with what effects. If it is the case, for example, that ceteris paribus, applicants from particular school, social class or ethnic backgrounds have lower likelihoods of receiving offers, then this would suggest that there is a pool 
of applicants from which more medical students could be drawn without reducing the academic quality of medical students in training.

Using individual-level data for two entire cohorts of medical student applicants in UK universities, we estimate a model to analyse the probability that an individual student receives an offer of a place. We find that gender, age, schooling, social class and ethnic background are major influences on whether a student receives an offer from a medical school. In particular, we find that there are significantly lower probabilities of receiving an offer to an applicant who (i) is from a non-white ethnic background, or (ii) is from a lower social class background, or (iii) attended either a comprehensive or further education college rather than a grammar or independent school. We also find strong effects relating to the particular medical school. More surprisingly, having controlled for personal characteristics and academic qualifications, we find that the other medical schools to which the applicant applied have a significant effect on the probability of receiving an offer from a particular medical school.

The dataset we have used provides information on the choice of medical school made by each applicant and we have exploited this in order to control for unobserved individual applicant-specific characteristics. We believe that this is important as offers are likely to be influenced by characteristics of applicants observed by medical schools in interview or references, for example, but not observed by the researcher. In one specification of the model we have allowed for the number of applications made by each applicant to be endogenously determined with the probability of receiving an offer. We find that allowing for correlation between the number of applications an individual makes and the unobserved characteristics is important as this makes a difference to the size of the derived marginal effects.

We have looked in some detail at the impact of later - though 'within-time' applications on the probability of receiving an offer and have discovered that not only is there a significant and substantial penalty associated with lateness, but also that the relatively disadvantaged groups - those, for example, from a non-white ethnic background or from a non-Independent school - suffer greater relative disadvantage the later is the application in the admissions round. We conclude from this particular finding that there is evidence to support a post-qualification admissions process, as advocated by the Schwartz Report (2004). More generally, our results suggest that changes in admissions procedures are necessary not only to create a fairer admissions 
process but also in order to ensure that medical schools draw on the best available talent in training the future medical workforce. 


\section{References}

Abbott, A. and Leslie, D. (2004), "Recent trends in higher education applications and acceptances”, Education Economics, 12, 67-86.

Andrews, D. W. K. (2001), “Testing when a parameter is on the boundary of the maintained hypothesis”, Econometrica, 69(3), 683-734.

Angel, C. and Johnson, A. (2000), "Broadening access to undergraduate medical education”, British Medical Journal, 321,1136-1138.

Arulampalam, W., Naylor, R. and Smith, J. (2004a), “A hazard model of the probability of medical school dropout in the UK," Journal of the Royal Statistical Society, Series A, 167, Part 1, 157-178.

Arulampalam, W., Naylor, R. A. and Smith, J. (2004b), "Factors affecting the probability of first-year medical student dropout in the UK: a logistic analysis for the intake cohorts of 1980-1992”, Medical Education, 38, 492-503.

Board of Medical Education, British Medical Association (2004) “The demography of medical schools: a discussion report”, British Medical Association, London.

Brewer, D. J., Eide, E. R. and Ehrenberg, R. G. (1999), "Does it pay to attend an eleite private college: cross-cohort evidence on the effects of college type on earnings?”, Journal of Human Resources, 34, 104-123.

Chevalier, A. and Conlon, G. (2003), “Does it pay to attend a prestigious university?”, Centre for the Economics of Education, Discussion Paper No: CEEDP0033.

Department for Education and Skills, "Improving the Higher Education Applications Process,” a Consultation Document, DfES, UK Government, September 2005.

Hayward, G., Sturdy, S. and James, S. (1997) "Estimating the reliability of predicted grades”, University and College Admission Service Report.

Hilton, S. and Lewis, K. (2004), “Opening doors to medicine,” Editorial Article, British Medical Journal, 328, pp. 1508-09.

Lawless, J. F. (1987), “Negative binomial and mixed Poisson regression”, Canadian Journal of Statistics, 15, 209-25.

Leslie, D., Abbott, A. and Blackaby, D. (2002), "Why are ethnic minority applicants less likely to be accepted into higher education”, Higher Education Quarterly, 56, 65-91. 
Light, A. and Strayer, W. (2002), “From Bakke to Hopwood: Does race affect college attendance and completion”, Review of Economics and Statistics, 84, 34-44.

Loury, L. D. and Garman, D. (1995), “College selectivity and earnings”, Journal of Labor Economics, 13, 289-308.

Lumb, A. B. and Vail, A. (1997), “Applicants to medical school: the value of predicted school leaving grades”, Medical Education, 31, pp. 307-311.

McManus, I. C. (1998a), "Factors affecting likelihood of applicants being offered a place in medical schools in the United Kingdom in 1996 and 1997: retrospective study”, British Medical Journal, 317, 1111-1117.

McManus, I. C. (1998b), “The selection of medical students at British universities in 1996 and 1997”, Report to the Council of Heads of Medical Schools, (www.chms.ac.uk/ 1998-CHMSreportStudentSelection1996and1997.pdf )

Medical Workforce Standing Advisory Committee. (1997), "Planning the medical workforce: third report”, London: Department of Health (http://www.doh.gov.uk/medical/mwsca3.htm).

Schwartz Report (2004), “Admissions to Higher Education Review,” http://www.admissions-review.org.uk.

Secretary of State for Education (2004), "Medical schools: delivering the doctors of the future”, Department for Education and Skills, London.

Seyan, K., Greenhalgh, T. and Dorling, D. (2004), “The standardised admission ratio for measuring widening participation in medical schools: analysis of UK medical school admissions by ethnicity, socioeconomic status, and sex”, British Medical Journal, 328, pp. 1545-46.

Shiner, M. and Modood, T. (2002), "Help or hindrance? Higher education and the route to ethnic equality”, British Journal of Sociology Education, 23, 209-232.

Smith, J. and Naylor, R. A. (2001), "Determinants of individual degree performance: Evidence for the 1993 UK university graduate population from the USR”, Oxford Bulletin of Economics and Statistics, 63, 29-60.

Stata 8 (2000), Stata Statistical Software, Release 8.0, College Station, TX: Stata Corporation.

Wooldridge, J. M. (2002), Econometric Analysis of Cross Section and Panel Data, The MIT Press, Cambridge, Massachusetts. 
Table 1a: Summary Statistics by Number of Applications

\begin{tabular}{|c|c|c|c|c|c|c|c|c|}
\hline & \multicolumn{4}{|c|}{1996} & \multicolumn{4}{|c|}{1997} \\
\hline & \multicolumn{2}{|c|}{$1-4$} & \multicolumn{2}{|c|}{5 or 6} & \multicolumn{2}{|c|}{$1-4$} & \multicolumn{2}{|c|}{5 or 6} \\
\hline & Mean & S.D. & Mean & S.D. & Mean & S.D. & Mean & S.D. \\
\hline Male & 0.485 & 0.500 & 0.495 & 0.500 & 0.475 & 0.499 & 0.483 & 0.500 \\
\hline \multicolumn{9}{|l|}{ Age groups } \\
\hline$<18$ & 0.093 & 0.215 & 0.040 & 0.196 & 0.073 & 0.260 & 0.031 & 0.173 \\
\hline 18 & 0.445 & 0.498 & 0.567 & 0.495 & 0.431 & 0.495 & 0.601 & 0.490 \\
\hline 19 & 0.189 & 0.394 & 0.192 & 0.394 & 0.205 & 0.404 & 0.188 & 0.390 \\
\hline 20 & 0.056 & 0.209 & 0.044 & 0.205 & 0.058 & 0.234 & 0.036 & 0.185 \\
\hline $21-23$ & 0.094 & 0.269 & 0.076 & 0.264 & 0.094 & 0.291 & 0.072 & 0.258 \\
\hline$>23$ & 0.124 & 0.283 & 0.081 & 0.273 & 0.139 & 0.346 & 0.073 & 0.260 \\
\hline \multicolumn{9}{|l|}{ Social class } \\
\hline SC I (Professional) & 0.265 & 0.477 & 0.366 & 0.482 & 0.238 & 0.426 & 0.355 & 0.479 \\
\hline SC II (Intermediate) & 0.376 & 0.484 & 0.372 & 0.483 & 0.388 & 0.487 & 0.363 & 0.481 \\
\hline SC IIINM (Skilled non-manual) & 0.117 & 0.283 & 0.082 & 0.274 & 0.115 & 0.319 & 0.074 & 0.262 \\
\hline SC IIIM (Skilled manual) & 0.089 & 0.281 & 0.086 & 0.280 & 0.089 & 0.285 & 0.083 & 0.275 \\
\hline SC IV (Partly skilled) & 0.072 & 0.214 & 0.044 & 0.204 & 0.059 & 0.235 & 0.047 & 0.211 \\
\hline SC V (Unskilled) & 0.014 & 0.102 & 0.010 & 0.098 & 0.011 & 0.106 & 0.011 & 0.104 \\
\hline Other & 0.067 & 0.207 & 0.041 & 0.197 & 0.100 & 0.300 & 0.068 & 0.252 \\
\hline \multicolumn{9}{|l|}{ Ethnic } \\
\hline White & 0.678 & 0.485 & 0.609 & 0.488 & 0.658 & 0.474 & 0.625 & 0.484 \\
\hline Black & 0.052 & 0.192 & 0.036 & 0.186 & 0.059 & 0.235 & 0.034 & 0.182 \\
\hline Indian & 0.066 & 0.321 & 0.126 & 0.332 & 0.066 & 0.249 & 0.126 & 0.331 \\
\hline Pakistani & 0.077 & 0.285 & 0.092 & 0.289 & 0.074 & 0.262 & 0.081 & 0.273 \\
\hline Other Asian & 0.047 & 0.264 & 0.080 & 0.272 & 0.050 & 0.217 & 0.071 & 0.257 \\
\hline Other & 0.032 & 0.181 & 0.034 & 0.182 & 0.035 & 0.184 & 0.030 & 0.171 \\
\hline Unknown & 0.047 & 0.162 & 0.023 & 0.151 & 0.059 & 0.235 & 0.033 & 0.178 \\
\hline \multicolumn{9}{|l|}{ Residence } \\
\hline North & 0.032 & 0.180 & 0.034 & 0.180 & 0.028 & 0.165 & 0.042 & 0.201 \\
\hline Yorkshire + Humberside & 0.058 & 0.246 & 0.066 & 0.248 & 0.050 & 0.217 & 0.067 & 0.250 \\
\hline North West & 0.080 & 0.306 & 0.110 & 0.313 & 0.085 & 0.278 & 0.105 & 0.307 \\
\hline East Midlands & 0.049 & 0.218 & 0.050 & 0.218 & 0.028 & 0.165 & 0.058 & 0.233 \\
\hline West Midlands & 0.065 & 0.273 & 0.084 & 0.278 & 0.069 & 0.253 & 0.080 & 0.271 \\
\hline East Anglia & 0.016 & 0.158 & 0.027 & 0.163 & 0.019 & 0.137 & 0.027 & 0.163 \\
\hline Greater London & 0.179 & 0.420 & 0.238 & 0.426 & 0.190 & 0.393 & 0.222 & 0.415 \\
\hline South East & 0.132 & 0.382 & 0.187 & 0.390 & 0.143 & 0.350 & 0.183 & 0.387 \\
\hline South West & 0.057 & 0.237 & 0.060 & 0.238 & 0.055 & 0.228 & 0.067 & 0.250 \\
\hline Wales & 0.040 & 0.205 & 0.045 & 0.206 & 0.043 & 0.202 & 0.046 & 0.210 \\
\hline Northern Ireland & 0.083 & 0.203 & 0.035 & 0.184 & 0.098 & 0.298 & 0.042 & 0.200 \\
\hline Scotland & 0.207 & 0.283 & 0.065 & 0.246 & 0.193 & 0.394 & 0.061 & 0.239 \\
\hline \multicolumn{9}{|l|}{ Proportion local } \\
\hline$<0.1$ & 0.190 & 0.327 & 0.109 & 0.311 & 0.190 & 0.392 & 0.108 & 0.310 \\
\hline $0.1-0.3$ & 0.113 & 0.388 & 0.199 & 0.399 & 0.119 & 0.324 & 0.213 & 0.409 \\
\hline $0.3-0.5$ & 0.161 & 0.396 & 0.201 & 0.401 & 0.157 & 0.364 & 0.207 & 0.405 \\
\hline $0.5-0.7$ & 0.030 & 0.355 & 0.171 & 0.376 & 0.031 & 0.174 & 0.183 & 0.386 \\
\hline $0.7-0.9$ & 0.082 & 0.340 & 0.143 & 0.350 & 0.085 & 0.278 & 0.139 & 0.346 \\
\hline $0.9+$ & 0.423 & 0.412 & 0.177 & 0.382 & 0.419 & 0.493 & 0.150 & 0.357 \\
\hline
\end{tabular}


Table 1a (cont'd): Summary Statistics by Number of Applications

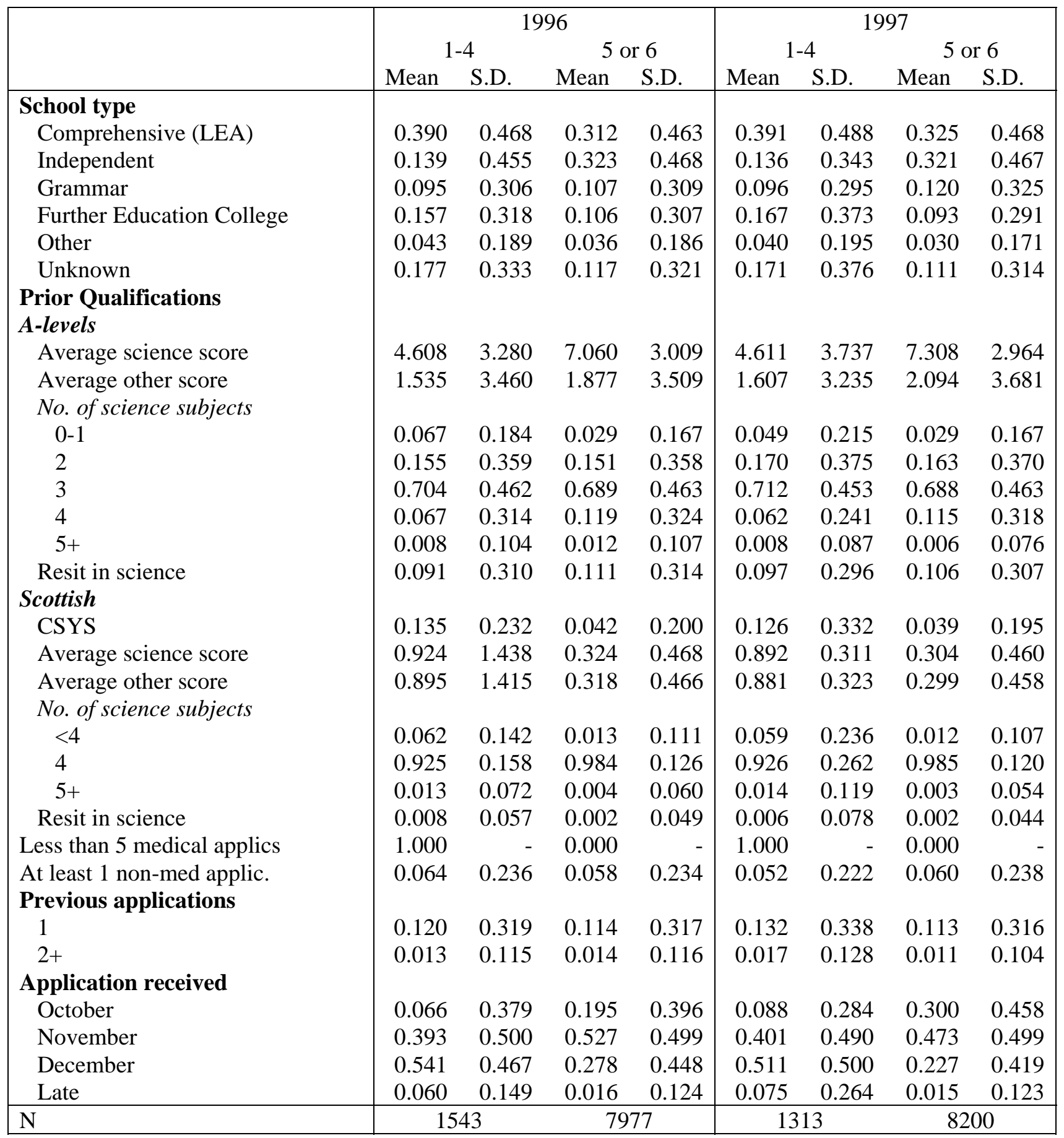

Note: Proportional local: is the proportion of an applicants medical school applications that are to a 'local' medical school. Local means that the residence of the applicant and the medical school are in the same region. The regions are taken as being Wales, Northern, Ireland, Scotland and the 9 standard regions of England. 
Table 1b: Summary Statistics by Offers Received

\begin{tabular}{|c|c|c|c|c|c|c|c|c|}
\hline & \multicolumn{4}{|c|}{1996} & \multicolumn{4}{|c|}{1997} \\
\hline & \multicolumn{2}{|c|}{ Zero } & \multicolumn{2}{|c|}{ At least 1} & \multicolumn{2}{|c|}{ Zero } & \multicolumn{2}{|c|}{ At least 1} \\
\hline & Mean & S.D. & Mean & S.D. & Mean & S.D. & Mean & S.D. \\
\hline Male & 0.557 & 0.497 & 0.446 & 0.497 & 0.531 & 0.499 & 0.447 & 0.497 \\
\hline \multicolumn{9}{|l|}{ Age groups } \\
\hline$<18$ & 0.033 & 0.178 & 0.060 & 0.237 & 0.019 & 0.136 & 0.050 & 0.217 \\
\hline 18 & 0.404 & 0.491 & 0.652 & 0.476 & 0.438 & 0.496 & 0.679 & 0.467 \\
\hline 19 & 0.204 & 0.403 & 0.183 & 0.387 & 0.203 & 0.402 & 0.181 & 0.385 \\
\hline 20 & 0.067 & 0.249 & 0.030 & 0.172 & 0.061 & 0.240 & 0.022 & 0.148 \\
\hline $21-23$ & 0.132 & 0.338 & 0.040 & 0.195 & 0.130 & 0.336 & 0.035 & 0.184 \\
\hline$>23$ & 0.161 & 0.367 & 0.035 & 0.183 & 0.150 & 0.357 & 0.033 & 0.179 \\
\hline \multicolumn{9}{|l|}{ Social class } \\
\hline SC I (Professional) & 0.304 & 0.460 & 0.383 & 0.486 & 0.288 & 0.453 & 0.375 & 0.484 \\
\hline SC II (Intermediate) & 0.351 & 0.477 & 0.389 & 0.487 & 0.347 & 0.476 & 0.380 & 0.485 \\
\hline SC IIINM (Skilled non-manual) & 0.108 & 0.311 & 0.072 & 0.259 & 0.089 & 0.284 & 0.073 & 0.260 \\
\hline SC IIIM (Skilled manual) & 0.094 & 0.292 & 0.081 & 0.273 & 0.089 & 0.285 & 0.080 & 0.271 \\
\hline SC IV (Partly skilled) & 0.063 & 0.243 & 0.037 & 0.189 & 0.058 & 0.233 & 0.042 & 0.200 \\
\hline SC V (Unskilled) & 0.017 & 0.128 & 0.006 & 0.077 & 0.016 & 0.125 & 0.008 & 0.087 \\
\hline Other & 0.063 & 0.243 & 0.032 & 0.175 & 0.113 & 0.317 & 0.043 & 0.203 \\
\hline \multicolumn{9}{|l|}{ Ethnic } \\
\hline White & 0.480 & 0.500 & 0.723 & 0.448 & 0.504 & 0.500 & 0.720 & 0.449 \\
\hline Black & 0.065 & 0.247 & 0.019 & 0.136 & 0.068 & 0.251 & 0.016 & 0.126 \\
\hline Indian & 0.137 & 0.344 & 0.101 & 0.301 & 0.132 & 0.339 & 0.107 & 0.309 \\
\hline Pakistani & 0.136 & 0.343 & 0.055 & 0.228 & 0.121 & 0.326 & 0.051 & 0.219 \\
\hline Other Asian & 0.097 & 0.296 & 0.059 & 0.236 & 0.083 & 0.276 & 0.058 & 0.234 \\
\hline Other & 0.044 & 0.206 & 0.026 & 0.159 & 0.039 & 0.195 & 0.025 & 0.155 \\
\hline Unknown & 0.040 & 0.196 & 0.017 & 0.131 & 0.053 & 0.224 & 0.024 & 0.153 \\
\hline \multicolumn{9}{|l|}{ Residence } \\
\hline North & 0.029 & 0.167 & 0.037 & 0.188 & 0.037 & 0.188 & 0.043 & 0.203 \\
\hline Yorkshire + Humberside & 0.057 & 0.231 & 0.070 & 0.256 & 0.061 & 0.240 & 0.067 & 0.250 \\
\hline North West & 0.085 & 0.280 & 0.119 & 0.324 & 0.092 & 0.290 & 0.109 & 0.312 \\
\hline East Midlands & 0.047 & 0.212 & 0.052 & 0.222 & 0.047 & 0.211 & 0.059 & 0.235 \\
\hline West Midlands & 0.084 & 0.277 & 0.080 & 0.271 & 0.079 & 0.269 & 0.078 & 0.268 \\
\hline East Anglia & 0.021 & 0.144 & 0.029 & 0.167 & 0.024 & 0.154 & 0.027 & 0.163 \\
\hline Greater London & 0.327 & 0.469 & 0.156 & 0.363 & 0.299 & 0.458 & 0.158 & 0.365 \\
\hline South East & 0.177 & 0.382 & 0.178 & 0.383 & 0.181 & 0.385 & 0.175 & 0.380 \\
\hline South West & 0.057 & 0.232 & 0.062 & 0.241 & 0.060 & 0.237 & 0.069 & 0.254 \\
\hline Wales & 0.033 & 0.177 & 0.052 & 0.222 & 0.044 & 0.205 & 0.047 & 0.212 \\
\hline Northern Ireland & 0.024 & 0.152 & 0.057 & 0.232 & 0.028 & 0.166 & 0.065 & 0.246 \\
\hline Scotland & 0.060 & 0.237 & 0.108 & 0.311 & 0.047 & 0.211 & 0.102 & 0.303 \\
\hline \multicolumn{9}{|l|}{ Proportion local } \\
\hline$<0.1$ & 0.141 & 0.348 & 0.108 & 0.310 & 0.134 & 0.341 & 0.108 & 0.311 \\
\hline $0.1-0.3$ & 0.146 & 0.354 & 0.214 & 0.410 & 0.155 & 0.362 & 0.232 & 0.422 \\
\hline $0.3-0.5$ & 0.174 & 0.379 & 0.210 & 0.407 & 0.190 & 0.393 & 0.207 & 0.405 \\
\hline $0.5-0.7$ & 0.136 & 0.343 & 0.157 & 0.364 & 0.150 & 0.357 & 0.170 & 0.376 \\
\hline $0.7-0.9$ & 0.121 & 0.326 & 0.143 & 0.350 & 0.128 & 0.334 & 0.134 & 0.341 \\
\hline $0.9+$ & 0.282 & 0.450 & 0.169 & 0.375 & 0.242 & 0.428 & 0.148 & 0.355 \\
\hline
\end{tabular}


Table 1b (cont'd): Summary Statistics by Offers Received

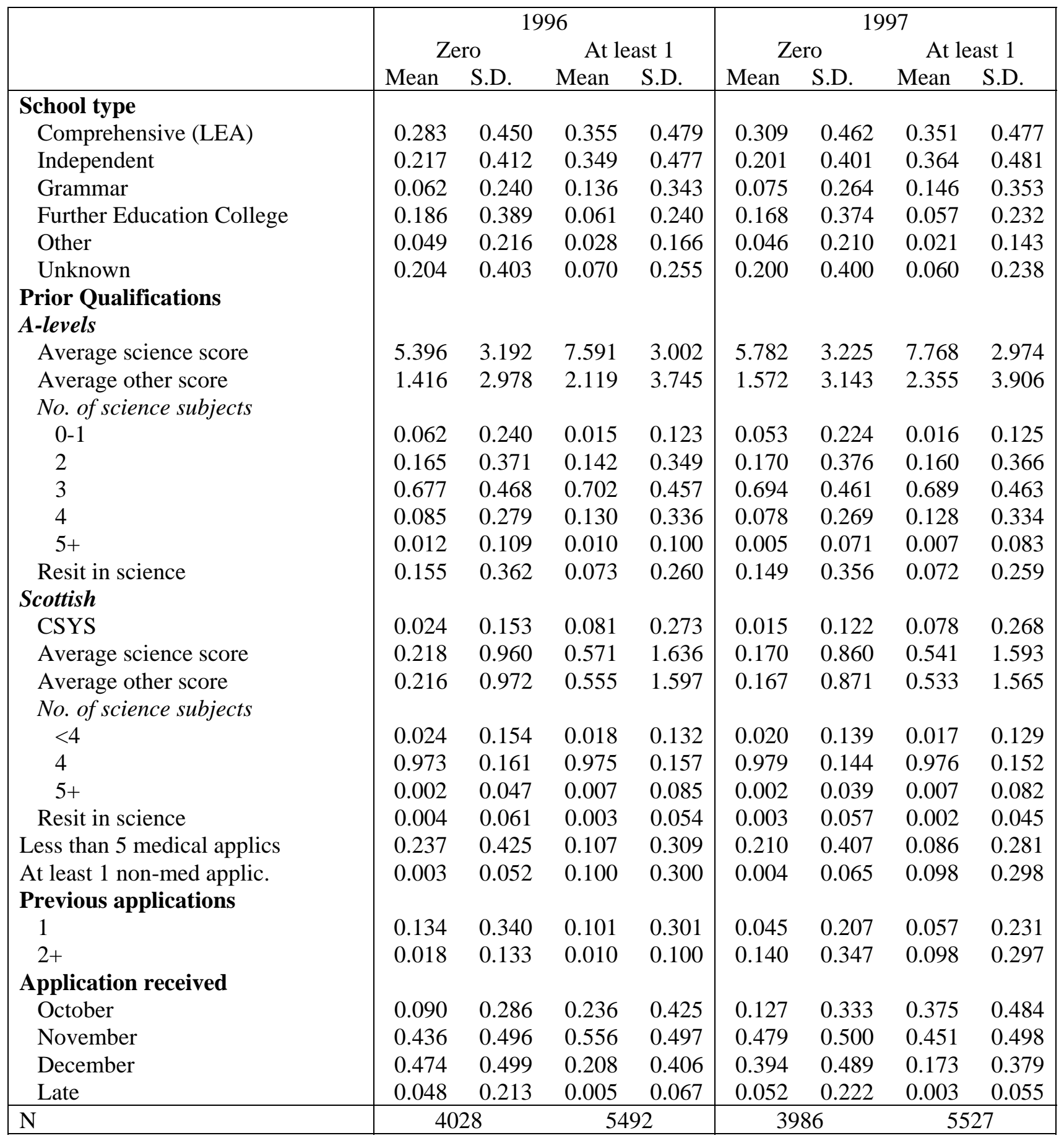


Table 2: Estimated Coefficients from Random effects probit models for the Probability of a Non-rejection

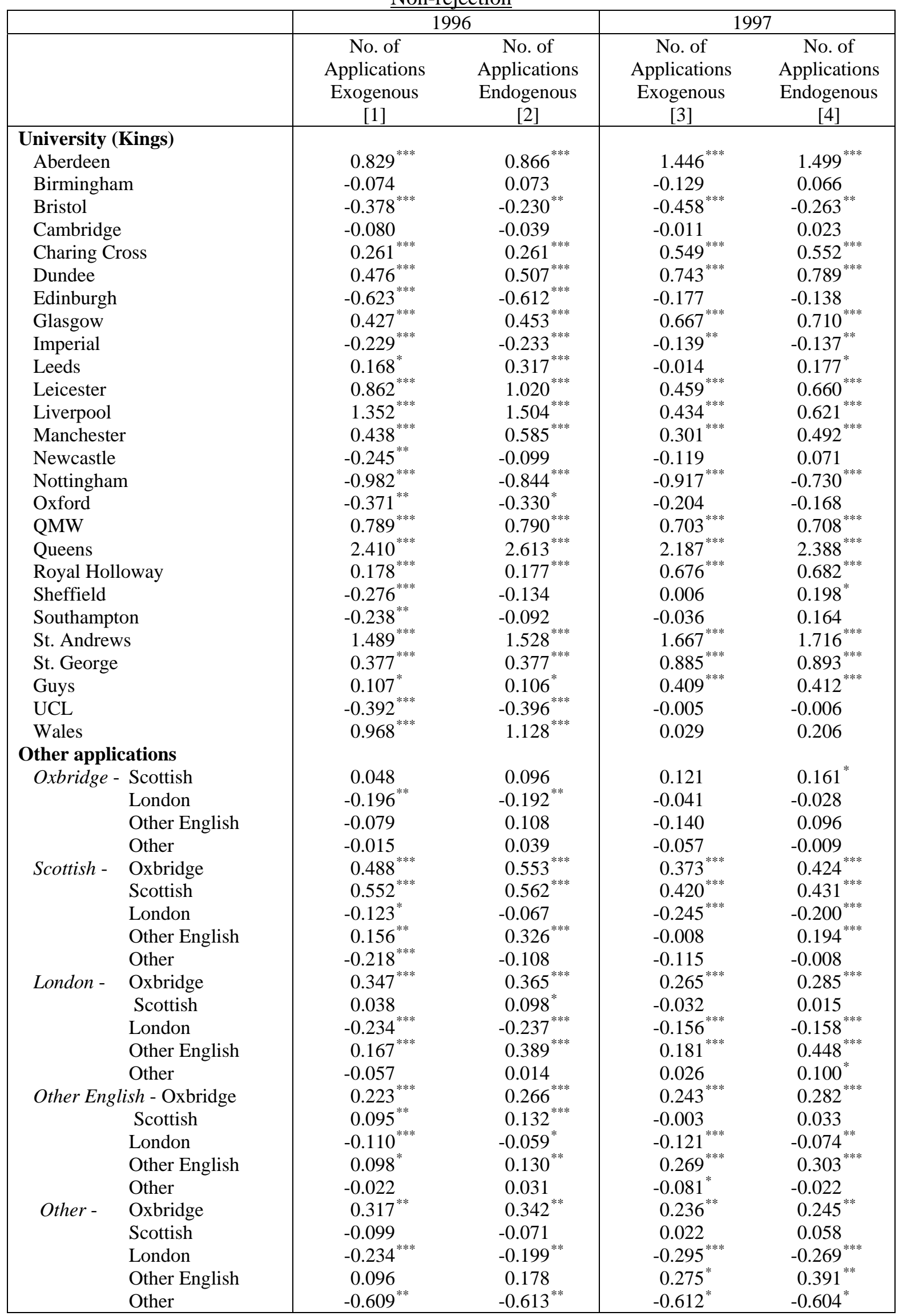


Table 2: Continued

\begin{tabular}{|c|c|c|c|c|}
\hline & \multicolumn{2}{|c|}{1996} & \multicolumn{2}{|c|}{1997} \\
\hline & $\begin{array}{c}\text { No. of } \\
\text { Applications } \\
\text { Exogenous } \\
{[1]}\end{array}$ & $\begin{array}{c}\text { No. of } \\
\text { Applications } \\
\text { Endogenous } \\
{[2]}\end{array}$ & $\begin{array}{c}\text { No. of } \\
\text { Applications } \\
\text { Exogenous } \\
{[1]}\end{array}$ & $\begin{array}{c}\text { No. of } \\
\text { Applications } \\
\text { Endogenous } \\
{[2]}\end{array}$ \\
\hline Male & $-0.250^{* * *}$ & $-0.248^{* * *}$ & $-0.232^{* * *}$ & $-0.231^{* * *}$ \\
\hline Age groups (18) & & & & \\
\hline$<18$ & $-0.139^{* *}$ & $-0.140^{* *}$ & $-0.132^{* *}$ & $-0.114^{*}$ \\
\hline 19 & $-0.085^{* *}$ & $-0.079^{* *}$ & $-0.156^{* * *}$ & $-0.148^{* * *}$ \\
\hline 20 & $-0.374^{* * *}$ & $-0.362^{* * *}$ & $-0.277^{* * *}$ & $-0.286^{* * *}$ \\
\hline $21-23$ & $-0.304^{* * *}$ & $-0.326^{* * *}$ & $-0.193^{* * *}$ & $-0.214^{* * *}$ \\
\hline$>23$ & $-0.352^{* * *}$ & $-0.373^{* * *}$ & $-0.143^{* *}$ & $-0.160^{* *}$ \\
\hline Social class (SC II) & & & & \\
\hline SC I (Professional) & $0.068^{* * *}$ & $0.065^{* *}$ & $0.049^{* *}$ & 0.035 \\
\hline SC IIINM (Skilled non-manual) & $-0.089^{* *}$ & $-0.084^{*}$ & $-0.137^{* * *}$ & $-0.131^{* * *}$ \\
\hline SC IIIM (Skilled manual) & -0.005 & -0.001 & -0.035 & -0.037 \\
\hline SC IV (Partly skilled) & $-0.125^{* *}$ & $-0.109^{*}$ & -0.084 & $-0.095^{*}$ \\
\hline SC V (Unskilled) & $-0.237^{*}$ & -0.204 & -0.085 & -0.113 \\
\hline Ethnic (White) & & & & \\
\hline Black & $-0.268^{* * *}$ & $-0.256^{* * *}$ & $-0.436^{* * *}$ & $-0.441^{* * *}$ \\
\hline Indian & $-0.306^{* * *}$ & $-0.318^{* * *}$ & $-0.322^{* * *}$ & $-0.335^{* * *}$ \\
\hline Pakistani & $-0.541^{* * *}$ & $-0.576^{* * *}$ & $-0.560^{* * *}$ & $-0.575^{* * *}$ \\
\hline Other Asian & $-0.372^{* * *}$ & $-0.392^{* * *}$ & $-0.371^{* * *}$ & $-0.387^{* * *}$ \\
\hline Proportion local $(<0.1)$ & & & & \\
\hline $0.1-0.3$ & -0.030 & $-0.300^{* * *}$ & 0.028 & $-0.217^{* * *}$ \\
\hline $0.3-0.5$ & 0.005 & $-0.203^{* * *}$ & 0.034 & $-0.170^{* * *}$ \\
\hline $0.5-0.7$ & 0.046 & $-0.298^{* * *}$ & 0.044 & $-0.261^{* * *}$ \\
\hline $0.7-0.9$ & 0.047 & $-0.166^{* * *}$ & 0.036 & $-0.172^{* * *}$ \\
\hline $0.9+$ & $0.255^{* * *}$ & $0.338^{* * *}$ & $0.183^{* * *}$ & $0.326^{* * *}$ \\
\hline School type (LEA) & & & & \\
\hline Independent & $0.078^{* * *}$ & $0.070^{* *}$ & $0.167^{* * *}$ & $0.160^{* * *}$ \\
\hline Grammar & $0.079^{* *}$ & $0.070^{*}$ & $0.094^{* *}$ & $0.088^{* *}$ \\
\hline Further Education College & $-0.193^{* * *}$ & $-0.202^{* * *}$ & $-0.164^{* * *}$ & $-0.161^{* * *}$ \\
\hline Prior Qualifications & & & & \\
\hline A-level Qualifications & & & & \\
\hline Average science score & $0.226^{* * *}$ & $0.226^{* * *}$ & $0.208^{* * *}$ & $0.205^{* * *}$ \\
\hline Average other score & $0.039^{* * *}$ & $0.039^{* * *}$ & $0.040^{* * *}$ & $0.040^{* * *}$ \\
\hline No. of science subjects (3) & & & & \\
\hline $0-1$ & $-0.436^{* * *}$ & $-0.424^{* * *}$ & $-0.368^{* * *}$ & $-0.371^{* * *}$ \\
\hline 2 & $-0.262^{* * *}$ & $-0.260^{* * *}$ & $-0.230^{* * *}$ & $-0.226^{* * *}$ \\
\hline 4 & $0.179^{* * *}$ & $0.176^{* * *}$ & $0.117^{* * *}$ & $0.120^{* * *}$ \\
\hline $5+$ & -0.005 & -0.010 & $0.219^{*}$ & $0.249^{*}$ \\
\hline Resit in science & $-0.569^{* * *}$ & $-0.579^{* * *}$ & $-0.513^{* * *}$ & $-0.521^{* * *}$ \\
\hline Scottish Qualifications & & & & \\
\hline CSYS & $0.617^{* * *}$ & $0.649^{* * *}$ & $0.344^{* * *}$ & $0.345^{* * *}$ \\
\hline Average science score & $0.267^{* * *}$ & $0.253^{* * *}$ & $0.215^{* * *}$ & $0.212^{* * *}$ \\
\hline Average other score & $0.064^{* * *}$ & $0.060^{* *}$ & $0.099^{* * *}$ & $0.094^{* * *}$ \\
\hline No. of science subjects (4) & & & & \\
\hline$<4$ & $-0.653^{* * *}$ & $-0.631^{* * *}$ & $-0.471^{* * *}$ & $-0.450^{* * *}$ \\
\hline $5+$ & -0.094 & -0.095 & -0.089 & -0.069 \\
\hline Resit in science & -0.311 & -0.320 & -0.176 & -0.189 \\
\hline
\end{tabular}


Table 2 Continued

\begin{tabular}{|c|c|c|c|c|}
\hline & \multicolumn{2}{|c|}{1996} & \multicolumn{2}{|c|}{1997} \\
\hline & $\begin{array}{c}\text { No. of } \\
\text { Applications } \\
\text { Exogenous } \\
{[1]}\end{array}$ & $\begin{array}{c}\text { No. of } \\
\text { Applications } \\
\text { Endogenous } \\
{[2]}\end{array}$ & $\begin{array}{c}\text { No. of } \\
\text { Applications } \\
\text { Exogenous } \\
{[3]}\end{array}$ & $\begin{array}{c}\text { No. of } \\
\text { Applications } \\
\text { Endogenous } \\
{[4]}\end{array}$ \\
\hline Less than 5 medical applics & $-0.293^{* * *}$ & $-0.573^{* * *}$ & $-0.176^{* * *}$ & $-0.507^{* * *}$ \\
\hline At least 1 non-med applic. & $-0.478^{* * *}$ & $-0.497^{* * *}$ & $-0.590^{* * *}$ & $-0.600^{* * *}$ \\
\hline 1 & 0.044 & 0.056 & 0.033 & 0.048 \\
\hline 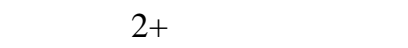 & 0.079 & 0.094 & -0.201 & -0.160 \\
\hline Application received (Nov) & & & & \\
\hline October & $0.253^{* * *}$ & $0.249^{* * *}$ & $0.324^{* * *}$ & $0.322^{* * *}$ \\
\hline December & $-0.378^{* * *}$ & $-0.373^{* * *}$ & $-0.310^{* * *}$ & $-0.296^{* * *}$ \\
\hline$\sigma_{\eta}$ & 0.576 & 0.362 & 0.565 & 0.347 \\
\hline$\rho$ & $0.249^{* * *}$ & $0.266^{* * *}$ & $0.242^{* * *}$ & $0.258^{* * *}$ \\
\hline$\theta$ & & $0.389^{* * *}$ & & $0.500^{* * *}$ \\
\hline
\end{tabular}

Notes:

1. ${ }^{* * *}$ significant at $1 \%,{ }^{* *}$ significant at $5 \%,{ }^{*}$ significant at $10 \%$.

2. For categorical variables the default category is denoted in parentheses. In addition to the variables listed, the model also included indicator variables for 'other' category in Social Class, Ethnicity and School type as well as indicator variables for Scottish 'Highers' and 'No Qualification' categories.

3. $\theta$ picks up the correlation between the individual specific errors in equations (1) and (4), and $\rho=\frac{\sigma_{\eta}^{2}}{1+\sigma_{\eta}^{2}}$. 
Table 3: Selected Marginal Effects of Variables on the Probability of Non-Rejection

\begin{tabular}{|c|c|c|c|c|c|c|}
\hline & \multicolumn{3}{|c|}{1996} & \multicolumn{3}{|c|}{1997} \\
\hline & $\begin{array}{c}\text { Simple } \\
\text { Random } \\
\text { Effects } \\
\text { Probit } \\
\\
{[1]}\end{array}$ & $\begin{array}{c}\text { Random } \\
\text { Effects } \\
\text { Probit } \\
\text { (Cond- } \\
\text { itional) } \\
\text { [2] }\end{array}$ & $\begin{array}{c}\text { Random } \\
\text { Effects } \\
\text { Probit } \\
\text { (Uncond- } \\
\text { itional) } \\
\text { [3] }\end{array}$ & $\begin{array}{c}\text { Simple } \\
\text { Random } \\
\text { Effects } \\
\text { Probit } \\
\\
{[4]}\end{array}$ & $\begin{array}{c}\text { Random } \\
\text { Effects } \\
\text { Probit } \\
\text { (Cond- } \\
\text { itional) } \\
\text { [5] }\end{array}$ & $\begin{array}{c}\text { Random } \\
\text { Effects } \\
\text { Probit } \\
\text { (Uncond- } \\
\text { itional) } \\
\text { [6] }\end{array}$ \\
\hline $\begin{array}{l}\text { Male } \\
\text { Age groups (18) }\end{array}$ & $-5.24^{* * *}$ & $-5.01^{* * *}$ & $-4.91^{* * *}$ & $-4.87^{* * *}$ & $-4.88^{* * *}$ & $-4.68^{* * *}$ \\
\hline 20 & $-7.84^{* * *}$ & $-6.67^{* * *}$ & $-7.21^{* * *}$ & $-5.82^{* * *}$ & $-5.60^{* * *}$ & $-5.58^{* * *}$ \\
\hline Social class (SC II) & & & & & & \\
\hline $\begin{array}{l}\text { SC I (Professional) } \\
\text { SC V (Unskilled) }\end{array}$ & $\begin{array}{l}1.42^{* * *} \\
-4.97^{*}\end{array}$ & $\begin{array}{l}1.31^{* *} \\
-2.14\end{array}$ & $\begin{array}{l}1.74^{* *} \\
-3.79\end{array}$ & $\begin{array}{l}1.02^{* *} \\
-1.80\end{array}$ & $\begin{array}{r}0.75 \\
-1.97\end{array}$ & $\begin{array}{r}1.65 \\
-1.80\end{array}$ \\
\hline $\begin{array}{l}\text { Ethnic (White) } \\
\text { Pakistani }\end{array}$ & $-11.34^{* * *}$ & $-10.18^{* * *}$ & $-8.68^{* * *}$ & $-11.78^{* * *}$ & $-10.44^{* * *}$ & $-8.66^{* * *}$ \\
\hline Residence (London) & & & & & & \\
\hline $\begin{array}{l}\text { Scotland } \\
\text { School type (LEA) }\end{array}$ & $-6.88^{* * *}$ & $-4.47^{*}$ & $-9.28^{*}$ & $-8.59^{* * *}$ & $-6.56^{* * *}$ & $-7.94^{* * *}$ \\
\hline $\begin{array}{l}\text { Independent } \\
\text { Further Education College }\end{array}$ & $\begin{array}{l}1.63^{* * *} \\
-4.04^{* * *}\end{array}$ & $\begin{array}{c}1.42^{* *} \\
-3.90^{* * *}\end{array}$ & $\begin{array}{c}2.71^{* *} \\
-3.64^{* * *}\end{array}$ & $\begin{array}{l}3.51^{* * *} \\
-3.45^{* * *}\end{array}$ & $\begin{array}{l}3.45^{* * *} \\
-3.27^{* * *}\end{array}$ & $\begin{array}{r}4.63^{* * *} \\
-3.13^{* * *}\end{array}$ \\
\hline $\begin{array}{l}\text { Prior Qualifications } \\
\text { A-levels }\end{array}$ & & & & & & \\
\hline $\begin{array}{l}\text { Average science score } \\
\text { Average other score } \\
\text { No. of science subjects (3) }\end{array}$ & $\begin{array}{l}3.16^{* * *} \\
0.55^{* * *}\end{array}$ & $\begin{array}{l}3.31^{* * *} \\
0.57^{* * *}\end{array}$ & $\begin{array}{l}3.81^{* * *} \\
0.54^{* * *}\end{array}$ & $\begin{array}{l}2.92^{* * *} \\
0.57^{* * *}\end{array}$ & $\begin{array}{l}3.04^{* * *} \\
0.64^{* * *}\end{array}$ & $\begin{array}{l}2.78^{* * *} \\
0.59^{* * *}\end{array}$ \\
\hline $\begin{array}{l}2 \\
4\end{array}$ & $\begin{array}{l}-5.50^{* * *} \\
3.75^{* * *}\end{array}$ & $\begin{array}{l}-5.00^{* * *} \\
3.66^{* * *}\end{array}$ & $\begin{array}{l}-5.38^{* * *} \\
3.65^{* * *}\end{array}$ & $\begin{array}{l}-4.85^{* * *} \\
2.47^{* * *}\end{array}$ & $\begin{array}{l}-4.57^{* * *} \\
2.60^{* * *}\end{array}$ & $\begin{array}{l}-4.85^{* * *} \\
2.04^{* * *}\end{array}$ \\
\hline $\begin{array}{l}\text { Resit in science A-level } \\
\text { Less than } 5 \text { medical applications } \\
\text { Application received (Nov) }\end{array}$ & $\begin{aligned}-11.91^{* * *} \\
-6.14^{* * *}\end{aligned}$ & $\begin{aligned}-10.32^{* * *} \\
-6.11^{* * *}\end{aligned}$ & $-9.41^{* * *}$ & $\begin{array}{l}-10.78^{* * *} \\
-3.69^{* * *}\end{array}$ & $\begin{array}{l}-9.73^{* * *} \\
-3.46^{* * *}\end{array}$ & $-8.30^{* * *}$ \\
\hline $\begin{array}{l}\text { October } \\
\text { December }\end{array}$ & $\begin{array}{r}5.29^{* * *} \\
-7.93^{* * *}\end{array}$ & $\begin{array}{c}5.14^{* * *} \\
-7.22^{* * *}\end{array}$ & $\begin{array}{c}5.94^{* * *} \\
-7.97^{* * *}\end{array}$ & $\begin{array}{r}6.81^{* * *} \\
-6.52^{* * *}\end{array}$ & $\begin{array}{c}7.69^{* * *} \\
-5.94^{* * *}\end{array}$ & $\begin{array}{r}7.99^{* * *} \\
-6.29^{* * *}\end{array}$ \\
\hline
\end{tabular}

Notes:

(i) Asterisks denote coefficient significance: ${ }^{* * *}$ at $1 \%,{ }^{* *}$ at $5 \%,{ }^{*}$ at $10 \%$.

(ii) Columns [1] and [4] use the coefficient estimates from the model where the endogeneity of the number of applications is not accounted for in the estimation. This is a simple random effects probit model.

(iii) Columns [2], [3], [5] and [6] use the coefficient estimates from the model that accounts for the endogeneity of the number of applications (Table 2, Columns [1] and [3]). In Columns [2] and [5] calculations, the marginal effects are conditional on the number of applications made. Columns [3] and [6] report unconditional marginal effects. See the Appendix for further details of the way in which these calculations are carried out. 
Table 4: Estimated Coefficients from Random effects probit models (with endogeneity) for the Probability of a Non-rejection for 1996: by application date

\begin{tabular}{|c|c|c|c|c|}
\hline & All & $\begin{array}{c}\text { Before October } \\
\text { 15th } \\
\end{array}$ & $\begin{array}{l}\text { October 15th- } \\
\text { Nov. 15th }\end{array}$ & $\begin{array}{l}{\text { November } 15^{\text {th }}} \\
\text { - Dec. } 15 \text { th }\end{array}$ \\
\hline Male & $-0.248^{* * *}$ & $-0.214^{* * *}$ & $-0.256^{* * *}$ & $-0.272^{* * *}$ \\
\hline \multicolumn{5}{|l|}{ Age groups (18) } \\
\hline$<18$ & $-0.140^{* *}$ & -0.153 & $-0.182^{* *}$ & -0.136 \\
\hline 19 & $-0.079^{* *}$ & -0.041 & -0.059 & -0.068 \\
\hline 20 & $-0.362^{* * *}$ & $-0.438^{* * *}$ & $-0.320^{* * *}$ & $-0.391^{* *}$ \\
\hline $21-23$ & $-0.326^{* * *}$ & $-0.358^{* *}$ & $-0.309^{* * *}$ & $-0.339^{* * *}$ \\
\hline$>23$ & $-0.373^{* * *}$ & $-0.535^{* * *}$ & $-0.415^{* * *}$ & $-0.294^{* *}$ \\
\hline \multicolumn{5}{|l|}{ Social class (SC II) } \\
\hline SC I (Professional) & $0.065^{* *}$ & $0.142^{* * *}$ & 0.045 & 0.012 \\
\hline SC IIINM (Skilled non-manual) & $-0.084^{*}$ & -0.037 & $-0.098^{*}$ & -0.013 \\
\hline SC IIIM (Skilled manual) & -0.001 & -0.050 & -0.009 & 0.030 \\
\hline SC IV (Partly skilled) & $-0.109^{*}$ & -0.205 & $-0.147^{*}$ & -0.036 \\
\hline SC V (Unskilled) & -0.204 & -0.611 & -0.131 & -0.130 \\
\hline \multicolumn{5}{|l|}{ Ethnic (White) } \\
\hline Black & $-0.256^{* * *}$ & -0.188 & $-0.285^{* * *}$ & -0.153 \\
\hline Indian & $-0.318^{* * *}$ & $-0.322^{* * *}$ & $-0.309^{* * *}$ & $-0.416^{* * *}$ \\
\hline Pakistani & $-0.576^{* * *}$ & $-0.467^{* * *}$ & $-0.581^{* * *}$ & $-0.757^{* * *}$ \\
\hline Other Asian & $-0.392^{* * *}$ & $-0.472^{* * *}$ & $-0.374^{* * *}$ & $-0.299^{* *}$ \\
\hline \multicolumn{5}{|l|}{ Proportion local $(<0.1)$} \\
\hline $0.1-0.3$ & $-0.300^{* * *}$ & -0.093 & $-0.267^{* * *}$ & $-0.581^{* * *}$ \\
\hline $0.3-0.5$ & $-0.203^{* * *}$ & -0.001 & $-0.211^{* * *}$ & $-0.335^{* * *}$ \\
\hline $0.5-0.7$ & $-0.298^{* * *}$ & -0.041 & $-0.257^{* * *}$ & $-0.673^{* * *}$ \\
\hline $0.7-0.9$ & $-0.166^{* * *}$ & -0.016 & $-0.168^{* * *}$ & $-0.336^{* * *}$ \\
\hline $0.9+$ & $0.338^{* * *}$ & $0.278^{* * *}$ & $0.197^{* * *}$ & $0.561^{* * *}$ \\
\hline \multicolumn{5}{|l|}{ School type (LEA) } \\
\hline Independent & $0.070^{* *}$ & 0.049 & $0.079^{* *}$ & -0.007 \\
\hline Grammar & $0.070^{*}$ & 0.082 & 0.050 & $0.240^{*}$ \\
\hline Further Education College & $-0.202^{* * *}$ & -0.106 & $-0.227^{* * *}$ & $-0.197^{*}$ \\
\hline \multicolumn{5}{|l|}{ Prior qualifications } \\
\hline \multicolumn{5}{|l|}{ A-levels Qualifications } \\
\hline Average science score & $0.226^{* * *}$ & $0.217^{* * *}$ & $0.239^{* * * *}$ & $0.235^{* * *}$ \\
\hline Average other score & $0.039^{* * *}$ & $0.036^{* * *}$ & $0.029^{* * *}$ & $0.066^{* * *}$ \\
\hline \multicolumn{5}{|l|}{ No. of science subjects (3) } \\
\hline $0-1$ & $-0.424^{* * *}$ & $-0.542^{* *}$ & $-0.272^{* *}$ & $-0.660^{* * *}$ \\
\hline 2 & $-0.260^{* * *}$ & $-0.229^{* * *}$ & $-0.220^{* * *}$ & $-0.434^{* * *}$ \\
\hline 4 & $0.176^{* * *}$ & $0.188^{* * *}$ & $0.183^{* * *}$ & 0.112 \\
\hline $5+$ & -0.010 & -0.182 & 0.030 & 0.106 \\
\hline Resit in science & $-0.579^{* * *}$ & $-0.412^{* * *}$ & $-0.617^{* * *}$ & $-0.592^{* * *}$ \\
\hline \multicolumn{5}{|l|}{ Scottish Qualifications } \\
\hline CSYS & $0.649^{* * *}$ & 0.498 & $0.416^{* *}$ & $0.840^{* * * *}$ \\
\hline Average science score & $0.253^{* * *}$ & 0.110 & $0.280^{* * *}$ & $0.247^{* * *}$ \\
\hline Average other score & $0.060^{* *}$ & 0.108 & -0.001 & $0.103^{* *}$ \\
\hline \multicolumn{5}{|l|}{ No. of science subjects (4) } \\
\hline$<4$ & $-0.631^{* * *}$ & 0.029 & $-0.754^{* * *}$ & $-0.536^{* * *}$ \\
\hline $5^{+}$ & -0.095 & -1.092 & -0.324 & -0.031 \\
\hline Resit in science & -0.320 & $0.000^{* * *}$ & -0.102 & $-0.521^{*}$ \\
\hline
\end{tabular}


Table 4 Continued

\begin{tabular}{|l|c|ccc|}
\hline & All & $\begin{array}{c}\text { Before October } \\
\text { 15th }\end{array}$ & $\begin{array}{c}\text { October 15th- } \\
\text { Nov. 15th }\end{array}$ & $\begin{array}{c}\text { November 15 } \\
\text { - Dec. 15th }\end{array}$ \\
\hline $\begin{array}{l}\text { Less than 5 medical applications } \\
\text { At least 1 non-med application }\end{array}$ & $-0.293^{* *}$ & $0.844^{* * *}$ & $-0.423^{* * *}$ & $-1.384^{* * *}$ \\
Previous applications (0) & $-0.478^{* *}$ & $-0.668^{* * *}$ & $-0.530^{* * *}$ & $-0.248^{*}$ \\
$\quad 1$ & & & & \\
$2+$ & 0.044 & -0.123 & 0.016 & 0.139 \\
Application received (Nov) & 0.079 & -0.181 & $0.366^{* *}$ & -0.299 \\
October & - & & & \\
December & $0.253^{* *}$ & & & \\
Late & $-0.378^{* *}$ & & & \\
\hline$\sigma_{\eta}$ & $-0.847^{*}$ & & & \\
$\rho$ & & $0.315^{* * *}$ & $0.334^{* * *}$ & $0.670^{* * *}$ \\
$\theta$ & & $0.240^{* * *}$ & $0.250^{* * *}$ & $0.401^{* * *}$ \\
$\theta$ & & $-2.024^{* *}$ & 0.281 & $0.833^{* * *}$ \\
\hline
\end{tabular}

Notes:

(i) See Notes to Table 2. 
Figure 1: Ratio of applications to places available by medical school

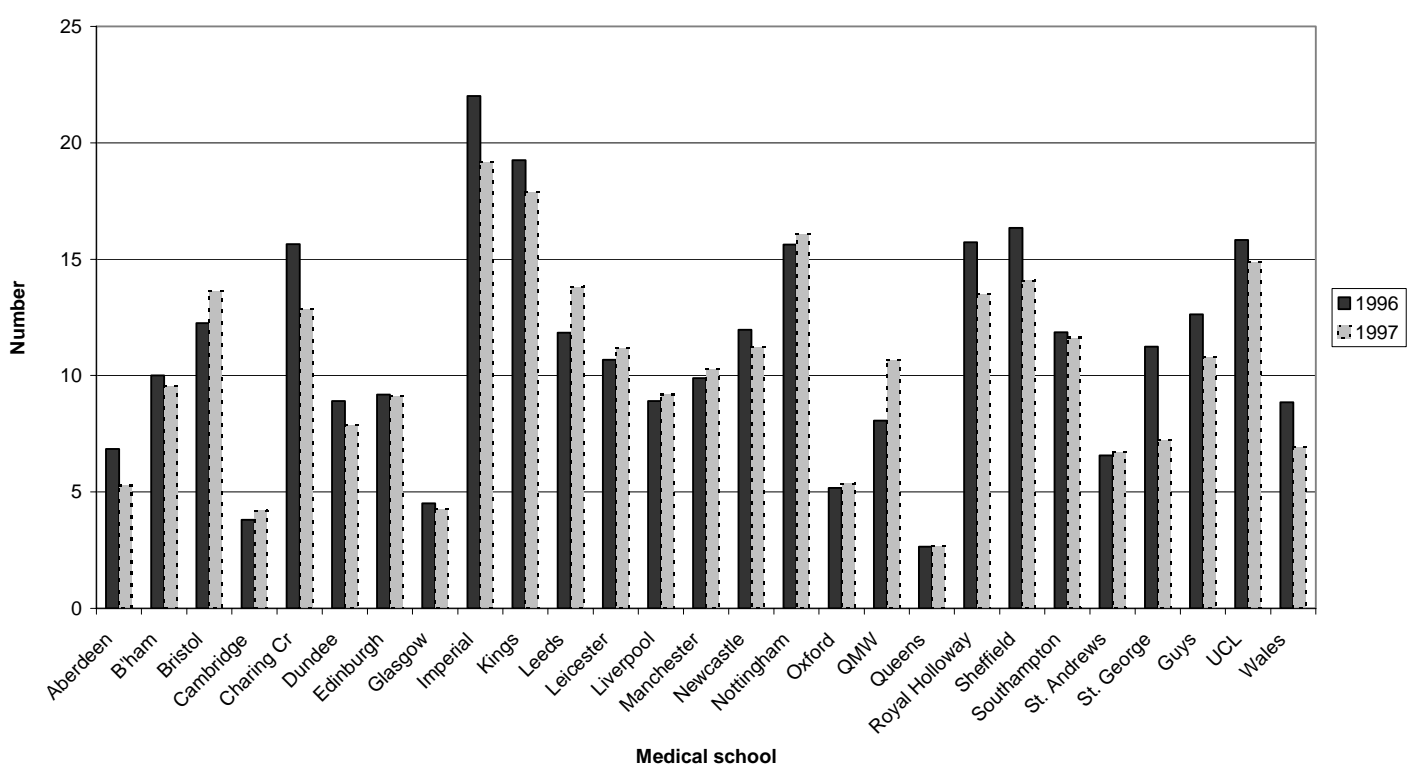

Figure 2: Proportion of offers to applications

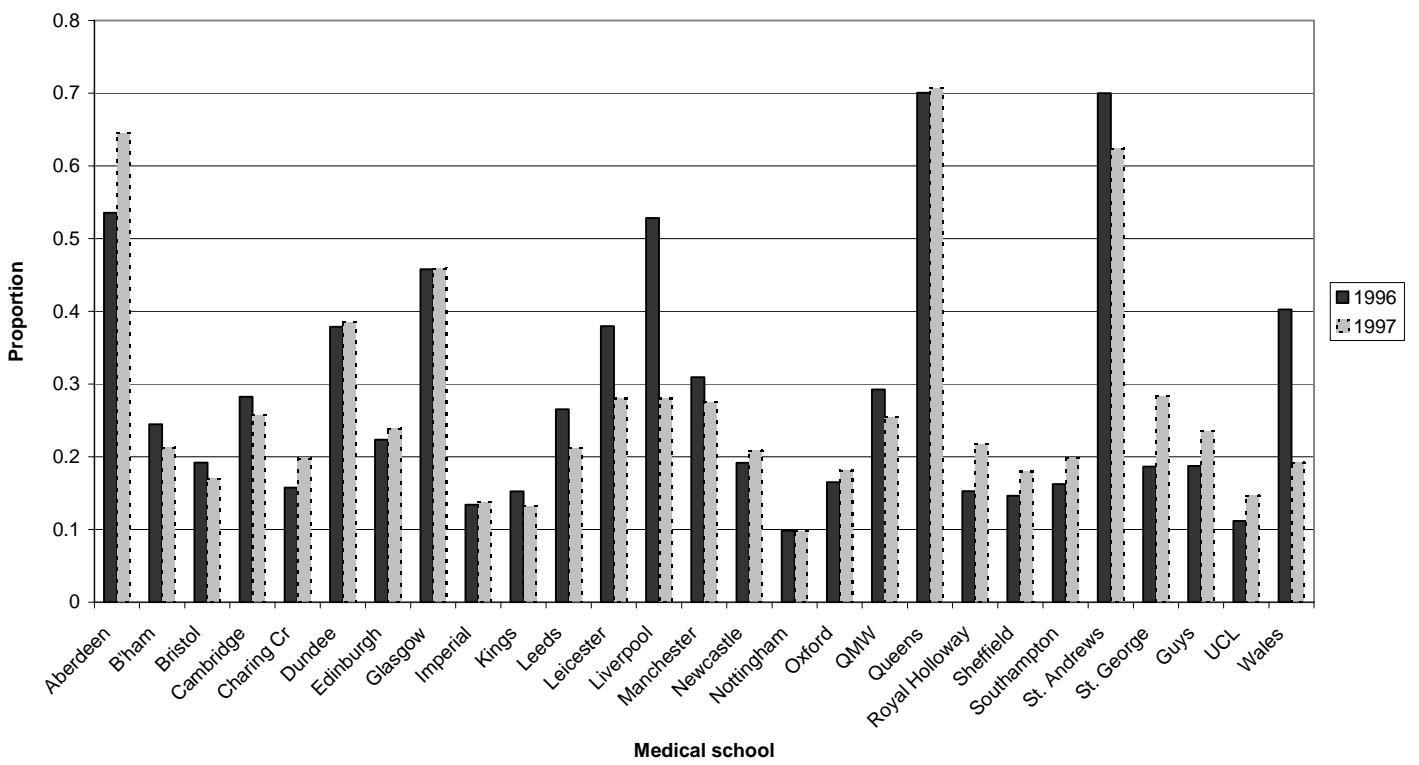




\section{Appendix: $\quad$ The derivation of marginal effects}

Since coefficients are not directly interpretable in the random effects probit model, we report the marginal effects associated with the estimated coefficients in Table 3. These are calculated as the difference between the sample averages of the probability of non-rejection predicted by the estimated model (equation (1)) when the variable takes two different values. When the variable is an indicator variable, the two values that are used are 1 and 0 . In the case of A-Level scores, the two values used are 8.66 and 8.00, which is the difference between an ABB and a BBB score. Columns [1] and [4] calculations use coefficients reported in Table 2 columns [1] and [3].

Although Columns [2], [3], [5] and [6] of Table 3 use the coefficients from the model that accounts for endogeneity of the number of applications made, there is a difference in the method of calculation of marginal effects as follows. The predicted probability of non-rejection used in Columns [2] and [5] of Table 3, uses the actual indicator variable, denoted as a in equation (4), for applying to less than 5 medical schools which is one of the explanatory variables in equation (1). However, in Columns [3] and [6] the changes are applied to equation (4) and the predicted outcome variable from this is then used in place of the actual number of applications, to facilitate the marginal effects calculations. ${ }^{5}$ To give an example of the calculation made in the case of the 'male' variable that enters both equations (1) and (4) would be as follows. First, we calculate the predicted probability for a=1 setting 'male' $=1$ and keeping all other variable values the same. We then convert the predicted probability into a 1 or 0 depending on whether it exceeds the cut-off probability or not. This predicted outcome is then used as the variable in the predicted probability calculation of equation (1) along with the value of 1 for 'male'. We then repeat the calculations using a value of 0 for 'male'. The difference in the average of these two predicted probabilities gives us the marginal effect for 'male'. Note, in all of these calculations, only the values for the variable under consideration is changed. All other variables remain the same.

\footnotetext{
${ }^{5}$ The cut-off points used for predictions are the same as the sample proportions of the number of applications made, which were 0.1621 and 0.1380 for 1996 and 1997, respectively.
} 